LNIVERSIDAD DE CHILE

FACULTAD DE FILOSOFIA, HUMANIDADES Y EDUCACION

CENTRO DE ESTUDIOS DE CULTURA JUDAICA

CUADERNO JUDAICO NO 11

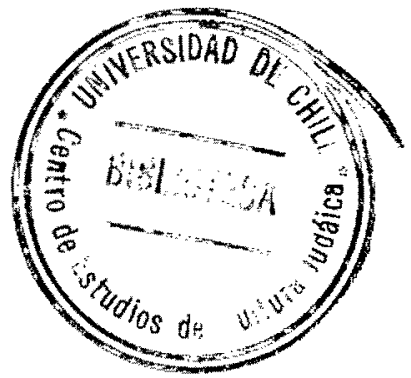

ETANA, Un Estudio Comparativo

Juan Calisto Rebolledo

Ana Maria Tapia Adler

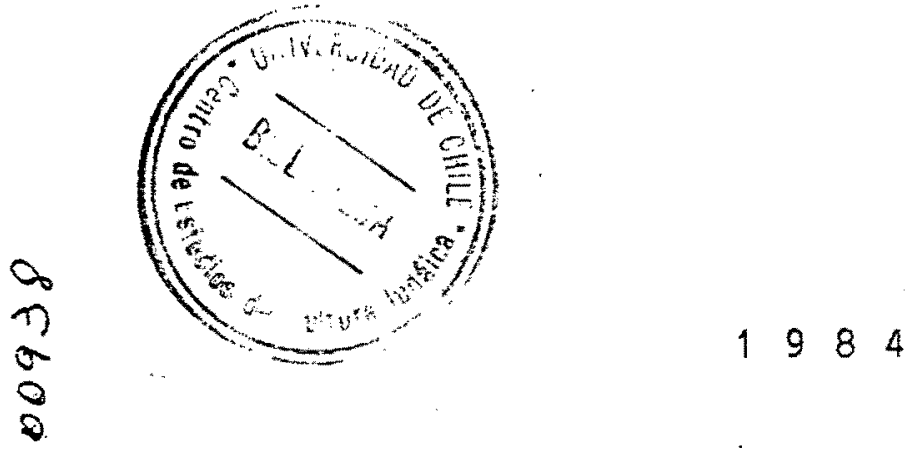


El presente, constituye un primer intento de estudio comparativo entre el Relato de Etana y el Antiguo Testa mento.

Penetrar en un texto antiguo que es poco conocido, mya que no se poseen ios originales y se trabajo a base de traducciones existentes- y pretender establecer un parale 10 con el Antiguo Testamento representa un verdadero desä fio.

Pese a esta linitación importante, los autores han querido enfrentar este desaffo y sorteando las dificultades, acencarse a 10 que ambos materiales, literario-historico entregan para establecer,en la medida de lo posible, algún punto original de acercariento.

otra limitante resulta del hecho que con excepción del Anticuo Testamento, no se posea documentos escritos so bre la vida, pensamiento e historia de los antiguos he = breos, lo que implica que muchos aspectos de su vida, no han podido ser conocidos.

En la realización del presente trobajo se ha tenido presente que en el Cercano oriente Antiguo la palabra escrita se trataba con respetio y cuidado.

Por ello, cuando los documentos que se estudian y que trasuntan dos mentalidades diferentes, presentan caracte risticas ajenas al pensamiento moderro, los autores se han esforzado por entenderlas, explicar las aparentes incoherencias, paradojas y contradicciones sin impugnar la exactitud de lus textos que constituyen su onica fuente de información.

Conscientes de la utilidad de realizar estudios compa rativos de la literatura, arte y religion de los pueblos del Cercano oriente Antiguo, en relación al Antiguo Testamento, es que entregamos este Cuaderno Judaico a la consideración de quienes se interesen por estos temas, haciendo presente que representa tan 5010 el primer paso y que cons tituye en sí una invitación a buscar ruevos elementos de juicio dentro del mismo tema.

Santiago, abril de 1984. 


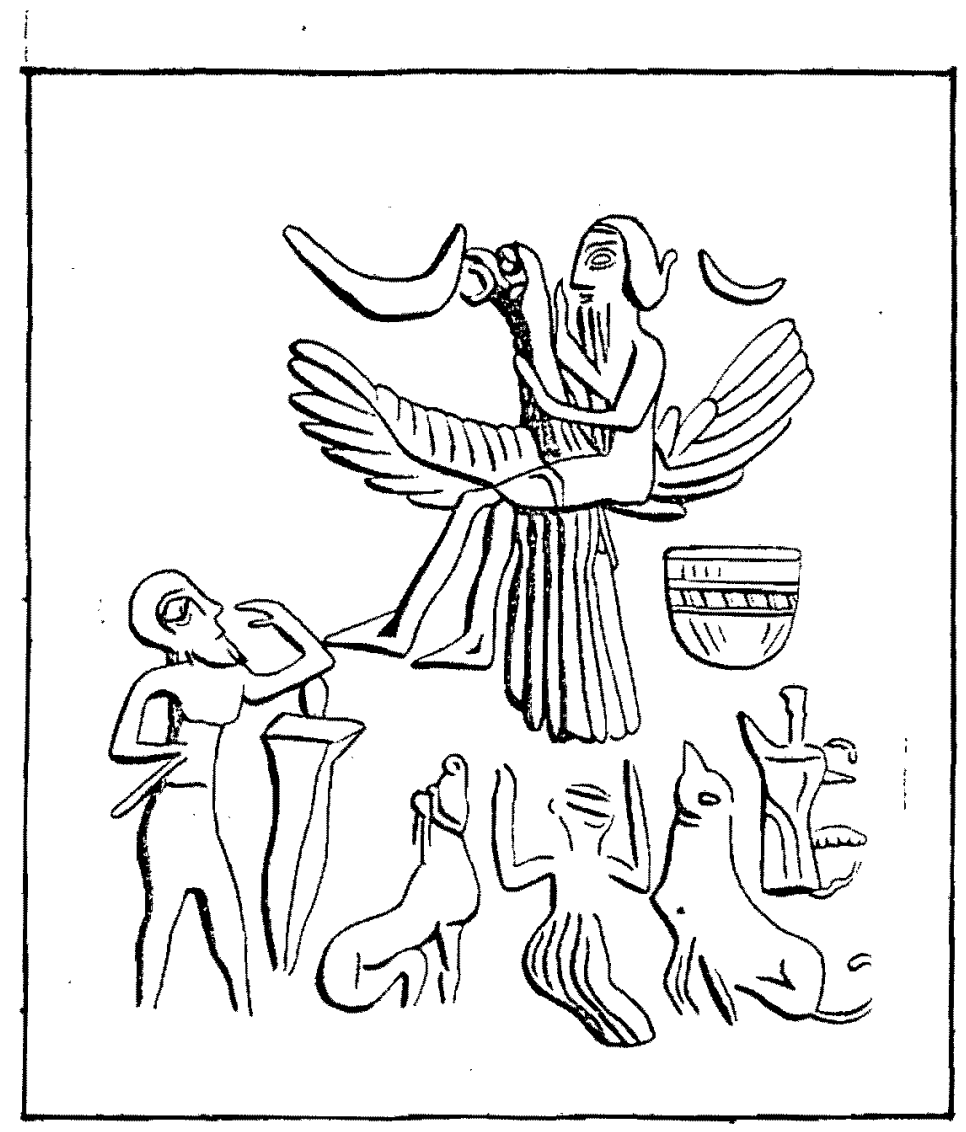

Letalle de la impresion de un sello cilindrico que "muestra al pastor Etana siendo llevado al cielo por un aguila". (ca.2254-2154 a.c.)

(Ver KEEL, othmar. Die welt der Altorientalischen Bildsymbolik und das Alte Testament. Benziger Verlag, Neukirchener veriag, 1972 ; pagina 178 , figura 271 . 


\section{PROBLEMAS HISTORICOS}

En la historia de Mesopotamia encontramos dos grupos humanos de vital importancia: Ellos son los sumerios $y$ los semitas; a quienes conocemos merced a la gran cantidad de documentos de la época que han liegado hasta nues tros diss, muchos de los cuales se remontan a los origenes mismos de la escritura.

De los primeros, nada se sabe acerca de su origen, pero si mucho de su civilización. Procedentes -probablemente- del Asia Central, se instalaron en el valle mesopotámico a mediados del tercer milenio.

En las ciudades sumerias, el hombre realizo algu ras de las obras más impresionantes en el campo de las artes y la arquitectura, la organización social y el pen samiento religioso.

La vida se desarrollaba apaciblemente alrededor del Templo, que era el verdadero centiro intelectual y economico, lo que explica en gran medida el por qué fue alli donde se invento y descrrolló un sistema práctico de es critura.

Con un gobierno en primera instancia democrático,en manos de asambleas que devienen en monarquia temporali. los súmeros ven surgir -a causa de los incesantes proble mas entre las ciudades-estados- la función de rey ( lu= gal) en carkcter hereditario, dinastico y las más de las veces despótico.

Para justificar esta nueva estructura politica surgio una verdadera "teología del reinado". En ella, el rey gobernante aseguraba la eleccion de su sucesor invocando la sanción del derecho divino:

A partir de la instauración de la monarquía -aproxi madamente en el 3000 - la historia sumeria se convierte en una narración continua de guerras y luchas en razón de que los reyes rivalizaban continuamente entre si por obtener el dominio de la región.

Uno de los reyes del periodo, Lugaizaggesi, monarca de la ciudad de Umma, conquisto en primer lugar a la ciu 
ded de Lagosh, $y$, posteriomente, al resto de las ciudades -estados sumerias: en este hecho, primer intento imperia lista, yace la base para la formación del primer imperio mesopotémico que surgire merced a la aparición de un nuevo elemento: Los semitas, nomades provenientes del desierto srabe.

El horizonte politico-cultural de Mesopotamia vio surgir a una de las figuras más notables del murido antiguo: Sargén, el grande: cficial semita que puso fin a la supremacia del sumerio lugalzaggesi y se destacó como el hábil organizador y administrador de un impenio que habria de perdurar durante dos siglos. Imperio que se inicia con la fusion de Sumeria y la imesopotamia septentrional en una so la nacion y bajo una sola autoridad.

la dinastia sargonida llego a su fin hacia el 2100. La historiografia antigua atribuye este hecho a factores de orden roligioso como una retribucion divina a algún de lito humano $y$, particularmente, como castigo a alguna trañs gresión rea! en contra de los dioses.

Akkad sucumbio ante. las arremetidas del "Dragon de la montaña": los gutti, el belicoso puebio muntañes que coali gados con los lulubies y los elamitas se enseñorearon del pais.

De esta situacion sacaron fuerzas las ciudades sume rias, las que se rebelaron y surgieron en un nuevo florecimiento: la era necsumeria, una época realmente importante en la arquicectura y las artes: pacifista en lo politico y grandemente religioso y contemplativo que no duro mucho.

El estado sumerio volvio a resurgir bajo la tercera di nastia de Ur: florecieron la escritura y la literatura y las escuelas sumerias se convirtieron en centros importan tes del saber. De esta época se han encontrado miles de documentos entre los que se incluyen el Primer codigo de dere cho, perteneciente a Ur Nämu.

Procedentes del desierto, nuevamente se infiltran grupos semitas que fundan nuevas dinastias: Mari, Babilonia, Larsa, Eshnunna...

Bajo la hábil conducción de Hammurabi, Babilonia asume el predominio de kescpotamia. Logra reconstituir el impe- 
rio de Sargón, "lo unifica y fortalece, 10 hace prospero por medio de la economia y orgánico por la administración de la justicia" (1).

Durante casi dos siglos se impuso la hegemonia babilónica, que debio ceder ante los embates de los "pueblos de las montañas" -hititas, hurritas y casitas-

ivientras Eabiionia languidecía, en el Alto Tigris se afirma el predominio Asirio: un pueblo esencialmente mili tar y disciplinado cuyo éxito se basa justamerite en su abrumador poderio militar.

Toda el Asia occijental cayó bajo su dominio. Su politica expansionista se realizo por etapas: Tiglatpileser I conquisto hasta el hediterráneo, Assurbanipal il bajo hacia Tiro; Tiglatpileser III vencio a las potencias del norte y a Babilonia, Sargón II vencio a Israel y Asahare dón logro penetrar en el delta egipcio.

El sucesor de Asaharddon, Assurbanipal, fue el Sarda riepalo de las leyendas, -el ultimo monarca asirio-, famoso "por la biblioteca que acerts a reunir en su palacio

real, no lo es menos por las operaciones bélicas, en las que el poder reunido por su padre es consolidado y afianzado conire toda insubordinacion" (2).

No abstante su poderio. Asiria al igual que otras po tencias de antaño, estaba destinada a caer y en el año612, ante el asalto combinado de Caldeos y Medos, Nínive ardio en liamas.

Mientras Asiria, herida de muerte, agonizaba, Babilo nia se rehacia con Nabopolasar, el fundador de una nueva dinastra.

Los babilonios suceden a los asirios en el poder. Na bucodonosor completa la obra de su padre: su ejército embistio y conquistó jerusalem y continuó su marcha hasta de tenerse en las fronteras de Egipto.

Este retorno al poder, aunque deslumbrador, es cort simo. Sin embargo, en élilas acciones guerreras van a la par con las obras civiles.

Con el surgimiento de los imperios semitas: akkadios, 
babilonios $y$ asirios, se continuo la corriente de inventarios y otros documentos legales escritos, en su totalidad, en icioma akkádico.

vesde la época sumerio se contaba con profesionales especializados en esos menesteres: Ios escribas, a quienes se exigía una preparación especial en la que la disciplina $y$ el adiestramiento eran riguroso.

La mayor parte de los estudios estaban dedicados a la enseñanza del sumerio y lo cierto es que casi toda la lite ratura sumeria ha llegado a nosotros a traves de las co = pias hechas por los eruditos posteriores.

La escuela devino, pues, en el centro cultural de la sociedad mesopotemica.

Uno de los hallazoos mas excepcionales lo constituyó el descubrimiento de la Biblioteca de Assurbanipal -ya men cioniada en párrafos anteriores-, libicada en el palacio dé Minive.

La Biblioteca fue creada por este monarca en el siglo UII y para este efectio Assurbanipai hacía copiar y compi lar las tabletas de todo su reino.

De $\in$ lia se exhumaron mas de 25.000 tabletas $y$ fragmen tos inscritas con texús bilingües (súmero-akkadicos), obras literarias y religiosas, conjuros y cartas, escritos sobre astronomia, nedicina, lexicografia, etc.

En este mundo, en el que el genio sumerio y el semita se unieron para legar a la humanidad los pilares de su civilización, debe encuadrarse el relato que nos interesa: la historia de Etaria, el rey pastor, quien en su incesante basqueda de la planta del riacimiento a fin de procurarse un nombre, ascendió al cielo montado en uña águila... 
II. TEXTO DE ETAMA

1) Generalidacies sobre el texto

El estudio del texto mesopotamico, nos enfrenta a tres problemas de orden metodologico, que consideramos necesario destacar:

- El primero dice relación con el hecho de que la versión liegada hasta nosotros, es una traduccion de la traducción del texto original. Esto significa que desconocemos al texto en su lengua original.

- El segundo problema es de orden cronologico: los relatos pertenecen a tres versiones diferentes, separadas entre si por algo mas de un milenio. Puede suponerse, además, que estas versionas tienen una fuente aún más alejada en el tiempo.

- El tercero radica en el hecho de que, aparte de las versiones aqui usadas, se sabe positivamente que existen otras que, desafortunadamente, desconocemos.

Para los efectos de este estudio, hemos considerado necesario efectuar una ordenación del relato; así es como aqui preseritaremos un orden cronologico y un orden logico dei mismo.

La ordenación cronológica tiene como anico objeto, el presentar paralelamente las tres versiones empleadas.

La ordenacion logica, en cambio, intenta presentar una versión coherente del relato mesopotámico, acorde a nuestro parecer.

En el mito de Etana, encontramos claramente dife renciados dos narraciones:

La fabula de "la serpiente y el sguila" que relata la amistad pactada entre ambos animales, quienes engeniran sus respectivas crias junto al arbol estoraque $y$ la "epopeya de Etana", que narra la historia del rey pastor que va en busca de la "planta del nacimientoli a fin de procurarse un nombre.

Ambas narraciones en sus orfgenes debieron haber sido totalmente independientes la una de la otra. Con 
el devenir del tiempo y merced a un elemento que resulta comán a ambas -la presencia de un águila- habrian sido ensambladas en una sola narracion a la que antepusieron un prólogo que situa los hechos en el tiempo y en el espacio.

La version que aqui presentamos ha sido confecciona da utilizando indistintamente los fragmentos de las di= versas versiones (respetando los cánones internacionales) y teniendo como columna vertebral la version neoasiria la que al parecer es la mejor conservada.

El ordenamierito de las versiones corresponde anica y exclusivamente a un orden logico de Ios acontecinien tos narrados acorde a nuestro punto de vista.

El orden que proponemos es el siguiente:

a) Prólogo

En un primer plano dejamos la asamblea de los gran des Annunnaki que decretan el destino. Fragmento que sirve para situarnos en el tiempo: los sucesos acaecen en el tiempo en que aún no se habia instituido la realeza.

b) La Fábula ce la serpiente y el zgui ia

El relato comienza en el momento en que realizan am bos animales su juramento y concluye con el "motivo de enlace" que sirve para ensamblar la epopeya. El aguila implora perdón a Shamash quien no lo concede, pero le de ja abierta una posibilidad de salvacion: "Aunque has jurado, yo no ire a ti. Pero he aquí, un hombre yo te en viare, el tomará tu mano". (Neoasirio ilI). Ese hombre es Etana:

"El águila abrio su boca diciendo a Etana: ifor que has venido?, dime ta" Etana abrio su boca, diciendo al aguila: "Amigo mío dame la planta del nacimiento, quita mi carga y produce para mi un nombre".

Alli concluye la fábula para dar paso al tercer pun to: la epopeya. 


\section{c) Epopeya de Etana}

Comienza con el relato de piudam, cuando es auscultada de un probable problema abortivo, y continúa despues, con el sueño de Prudam.

Etana se resuelve a encontrar la planta del nacimiento: antes de partir suplica a Shamash, quien le dice: "Sigue tu camino, cruza la montaña, al ver un pozo, examina su interior, dentro de él yace un âguila".

He aqui como rivévamente, el elemento aguila une los relatos. A partir de aca, sigue una sola narracion ya bien ensamblada: "Arriba, yo te llevaré al cielo de Anu". El relato termina en desastre:

"el sguila cayó, y ell a su ledo...

el sguila ha sido maguilada, de Etana...."

"La planta Que le habria satisfecho su deseo, no pudo encontrar la. Ast los dioses... llegaron al fina!, los años se cumplieron".

El texto finaliza con la muerte del rey pastor.

Ciertamente lo fragmentario dal texto invita a hacer trabajar la imaginación, no obstante ello hemos quericio ce ñirnos estrictamerte a lo escrito. 
2) El texto 


\section{R. BABILONIO}

\section{Babilonio antiguo A 1}

$(1800$ a.e.c.)

$-I-$

Los grandes finnunaki que decretan el destino

sentáronse del iberando acerca de la tierra.

Aquellos que crearon las regiones, que establecieron las condicio nes.

Los Igigi, que eran hostiles a la humanidad

un tiempo fijo para la humanidad decretaron

La gente oscura, en su totalidad, no habian establecido un rey.

En ese entonces ninguna tiara ha bía sido ceñida, ni corona;

Tampoco un cetro habia sido en gastado en lapislázuli:

los santuarios no habían sido construidos en modo alguno. Los siete habían obstruido las puertas contra los colonos.

Cetro, corona, tiara y cayado
R. ASTPIO NEOIO

R. NEO ASIRIO

Neo-fisirio (Nírive, 635 a.e.c.)

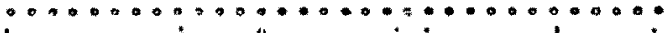

Los grandes Annunnak i gite decretan el destino

Se sentaron intercambiario sus pareceres acerca de la tierra. Los que crearon las cuatro regiones......................

todos los Igigi eran hostiles...

El ........... no había establecido un rey.

En aquellos dias ninguna tiara había sido ceñida, ni corona;

tampoco un cetro hajía sido engas tado en lapislázuli ;

las regiones no hablan sido creadas en modo alguno.

Los divinos Siete contra el pue blo obstruyeron las puertas contra los colonos osstruveron... (n)..... Los Igigi se habian narchido de la ciudad.

Ishtar un pastor para el pueblo 
yacen depositados ante finu en el cielo;

no hay consejo nara su qente.

(Entonces) la realeza bajó

del Cielo.

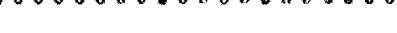

$\ldots \ldots \ldots$ (faltan $i \vec{i}, i j, i v)$

\section{Bnbilonio antiguo A 2}

"Oue la senda se pierda para El, que no encuentre al camino!

que la montaña lo rechace de su paso!

que el arina puntiaguda se dirija derecho a el

Ellos se juraron este jura inento mutuenente.

Todos fueron concebidos, todos nacieron:

A la sombra del árbol esto raque, engendra la sempien te;

en su copa engendra el áquila.

Cuando la serpiente ha cazado un leopardo, un tiare,

ei aguila se alimenta, su cría se alimenta.

y un rey busca para la ciudad. Enlil inspecciona los distritos

del cielo................... mientras continúa el buscando...

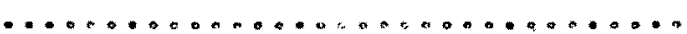

en la tierro un rey.............

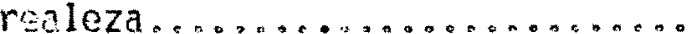
Entonces su corazón incitó Enlil.

los dioses ...

Asirio Medio (1000 a.e.c.)

-1 -

$"$

Que el arme Duntirouda si dirija derecho a él.

que Shamash lo escoja de entre los asesinos.

que Shanash entregue el nal yado en la llanurê!"

En la copa del árbcl el águi la emgendra.

al pie del ârbol estoraque engendra la serriente.

a la sombra del artol estora que.

El áquila y la serpiente formaron su amistad,

tomsndose al juranento de per manecer compcĩieros

el doseo de su corazón se manifestaron inutuamente,
Hac-Asirio

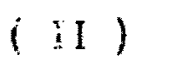

"Ven, levantémonos.....

liemos jurado por el mundo infe rior..."

El juramento que juraron ante el valiente Shamash:

"Al que transgrediere los vinculos de Shamasin.

que Shamash los entregue para mal al verdugo!

Al que transarediere los vincu. los de Shamash.

que la montaña le quite su paso, que el arma puntiaguda se dirija derecino a él.

que la trampa, la maldición de Shamash. lo derribe y lo cace!" Cuando hubieron jurado el juramento por el mundo inferior 
Despućs que su cria hubo crecido en edad y estatura, sus alas hubieron adquiricio,

el aqui ia tramómaidad en su corazón:

"Mi cria ha crecido en edad $y$ porte,

ellos partirán a buscar.......

elios buscarán la (s) plan -

$\mathrm{ta}(\mathrm{s})$.

Entonces yo devoraré la cría

de la serpiente.............. ascendere $y$ en el cielo

yo habitaré...................

Quiên hay que .............?

El pequeño aguilucho, excelen te en sabiduría,

al aguila, su padre (estas) palabras dirigio:

"Padre mín............... $0000000000,000,00000000$ ........ (resto del anverso destruido)............

(reverso)

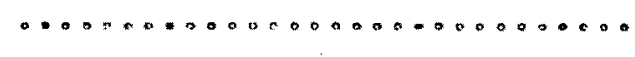

$\ldots \ldots \ldots \ldots, \ldots \ldots \ldots \ldots \ldots \ldots \ldots \ldots$

La serpiente deposito su cargo ante sus crias.

piiro alrededor, sus crías no estaban!
La serpiante sale a cozor. Cuando ovejas salvejes o ca bras salvajes

la serpicnte ha cazado,

el aguila se alimenta, se re tira.

su cría se alimenta.

Cuando la serpiente ha caza do cabras montesas, gacelas de la estepo,

el áquila se alimenta, se re tira, su cria se alimenta-

Cuando Ia serviente ha cazado el lecpardo de la estepa, las criaturas de la tierra, el âquila se alimenta, se re tira, su cría se al inentaDespues que la cría del águi la

hubo crecidio en edad y estatura,

hubo adquirido porte

el áquila a la cría de su anico,

desoar puso en su mente. se levantaron y subieron a la montaña.

Cada día vigilaban ......

Cuando el áquila ha cazado un busy salvaje o un asno salya je.

la serpiente se alimenta, se retira, su cina se alimenta.

Cuando la serpiente ha cazado cabras montesas o gacelas,

al aguila se alimenta se reti ra. su cría se alimenta.

Cuanco el águila ha cazado ove jas salvajes o cabras salvajes,

la serpiente se alimenta. se retira, su cría se alimenta.

Cuando la serpiente ha cazado lecpardos o tigres del campo

el áquila se alimenta, se retira, su cría se al imenta.

El águila recibió su alimento; su cría creció en edad y estàtura.

Cuancio su cría hubo crecido en edad y estatura,

el corazón del ấguila tramó maldad:

y cuando su corazón trano maldad resolvió en su mente devorar la cria des su anilgo.

El águila abrió su boca, diciendo a su cría: 
Con sus garras rasca el suelo; el polvo del nido cubre el cielo.

la serpiente..............

$$
\text { llora }
$$

sus lagrimas fluyendo ante Shamash:

"En tí pongo mi confianza, va liente Shamash!

Al aguila extendi mi buena yo luntad,

venere $y$ honré tu juramento, no opuso maldad contra mi anigo

Ahora êl, su nido esta entero Dero mi nido ests destrozado

el nido de la serpiente ha llegado a ser una elegía.

Sus aquiluchos están enteros, mis crias no estan;

bajo y devoró ini descendencia, Stibelo, on Shamash, que s! que persigue maldad

Tu red es el amplio campo.

tu trampa es el lejano cielo; que el áquila no escape de tu red,

el hechor de maldad y abomina ción

Que opone maldad contra su ami go. "îe comerể la cría de la serpien te, la serpiente ...

subiré al cielo para poder ha bitar alli.

y descenderé a la copa del árbol a comer el fruto".

El pequeño aguilucho, excelante en sabiduria.

estas palabras a su padre diri gió:

"No conas padre mío! la red de Shamash puede cogerte;

la trampa la maldición de Shamash puede derribarte $y$ cazarte.

Al que transgrede los yinculos de Shamash

10 entregară Shamash a él para ma! al verduao!"

Pero él no las oyó, no atendió a las palabras de su nijo;

descendió y devoró la cría de la serpiente.

.. a la mitad del día la ser piente llego

trayando su carga de carne. A la entrada del nido

arrójala a su cria.

Cuando la serniente miró en derredor; su nido no estaba; cuando se inclínó no lo vio.

Con sus garras, rasca el suelo; El polvo del nido cubre el cielo. 
Moo-Asirio (III)

Le. serpiente yace y llora.

sus lagrimas fluvendo ante Shamash:

"En ti pongo mi confianza, yaliente Shamash!

A! aguila extencis mi buena voluntad.

Ahora mi nido ..............

ni nido está destruido .......

destrozadas estan mis crias......

bajó y devoró $\mathrm{mi}$ descendencia.

Sábelo sú, oh Shamash, la maldad que me ha hecho.

Ciertamente, on Shamasin, tu red es la ancina tierra,

tu trama es el lejano cielo: Gue el águila no escape de tu red, acuel malhechor, $Z u$, que opone maldad contra su ainigo".

Cliando Shamash oyó la queja de la serpiente,

Shamasi abrió su boca, diciendo a la serpiente:

"Sigue tu camino, cruza la montaña. yo atere para tí un buey salvaje: fibre su interior, rasga su vientre, planta tu morada en su vientre, Toda clase de ave del Cielo descen derá a devorar la carne:

el águila descenderâ con ellos a devorar la carne

Duesto que no conoce su infortunio. Buscando la suculenta carne, proce derá cautelosamente, 
tentando 10 recondito del interior.

Cuando entire en el interior, cóge-

lo tú por sus alas,

arranca sus alas, sus alones y sus garras,

desplifialo y tíraio dentro de un pozo.......

Dejalo miorir la muerte de hambre y sed!"

Al valiente Shamash,

la serpiente fue y cruzó la montaña .

Cuando la serpiento alcanzó

al

buey saivaje.

abrio su interior, rasno su vientre, plant5 su morada en su vientre.

Toda clase de ave del Cielo descen dió a deyorar la carne

Si el águila hubiase conocido su infortanio

no hubiera comido con las aves!

El águila abrío su boca, diciendo a sul crisa:

"len Lajemos y devorenos la carne de este buey salvaje!"

El pequeño anuilucho excelente en sabiduria,

al aguila su padre, estas palabras dirigió:

"fio bajjes padre mio! Quizá

dentro del buey salvaje aceche la serpiente!" 
El águila sin consultar con su cora zón, dijo estas palabras:

"Bajaré y comeré la carne del buey salvaje!

¿Corro podría la serpiente devorarme?

El no las oyo, no atendió las palabras de su hitio.

Eejó y se posó sobre el buey salvaje.

El áquila inspeccionó la carne, exa mins sus partes delanteras y traseras.

Nulavmerite inspecciono la carne, examina sus partes delanteras y traseras.

Srocediendo cautelosamente, tienta lo recondito del interior.

Cuando entró en el interior, la ser piente lo cogis por sus alas:

"i....!"

El águil a abrió su boca, diciendo a la serviento:

"Ten compasion de mí y te harẻ un regalo de bodas como a un novio!"

La serpiente abrí su boca diciendo al águila:

"Si te suel to cóno respondere yo $\vec{c}$ Shanash en lo alto?

tu castigo se tornaria contra mí

que debiera imponer castigo sobre tî!"

Arrancó sus alas. . sus alones y sus garras, 
"Oh Shamash, toma mi mano

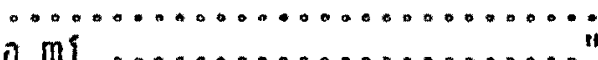

Shamash abrio su boca di"

ciendo al gauila:

Te has comportado perversa -

mente.....................

Lo aborrecido por los dioses y lo vedado en yerdad $\mathrm{co-}$ miste"

Shamash abrio su boca,dicien do al aguila:

To eres malvado $y$ me has ofendido gravemente!

Lo aborrecido por los dioses y lo vedado, en

verdad comiste lo desplumó y lo tiró dentro de un pOzO.

diciencio: "Morirá su muerte de ham bre y sed!"

... el águila diariamente suplica

a Shamash

"He de morir en el pozo,

Quiôn sabe cómo tu castigo fue impliesto sobre mi?

Sálvame la vida a mi, el águila,

y cantare tu nombre hasta la eternidad!"

Shamash abric su boca, diciendo al aquila:

"Tu eres malvado $y$ me has ofendido gravemente!

lo aborrecido nor los dioses y 10 vedado, en verdad comiste

Aunque has jurado, yo no irê a ti.

Pero, he aqui, un hombre yo te enviare, el

tomará tu mano"

Etana diariamente suplica a Sha mash:

"Tu has consumido, oh Shamash, mis más gordas ovejas.

bebiendose la tierra la sangre de mis corderos. 
rinque has jurado, yo no iré a ti.

Pero, un hombre yo

te enviars, el

tomara tu mano".
Yo he honrado los dioses y reve renciado a los espiritus

Les sacerdotisas del oráculo han hecho lo necesario a mis ofrendas:

los corderos, con sus deguelles, han hecho lo necesario a los dioses.

Oh señor, que salga de tu boca:

otergome la planta dal nacimiento, inuestrane la planta del naci miento.

quita mi carça $y$ produce para mí un ncmbie!"

Shamash abrió su boca, diciendo a Etana:

"Sigue tu camino, cruza la montaกิว;

al ver un pozo, examina su intericr.

dentro de el vace un águila;

e! ta mostrara la planta del nacimiento"

Al mandato del valiente Shamash, Etana siquió su camino, cruzó la nontaña:

cuando yio el pozo, exaning su interior:

dentro de él yacia un águila.

en la forma como Shamash lo había hecho esperarlo. 
For su mano cogióle......... Al octavo mes lo hizo pasar por su pozo

El Sguila, habiendo recibido el alimento como rugiente león

ganó fortaleza.

El Sguila abrió su boca,diciendo a Etana:

"Pli amigo, estamos verdaderainen te unidos en amistad, yo y ti!

of tan sólo lo que de ini deseas $y$ yo te 10 conceders".

Etana abrió su boca, diciando a! Sguila:

"................ algo oculio".
El ăguila abrịo su boca, diciendo estas palabras a Sha mash, su señor:

11

la cría de un ave...

lo conduzca hacia acá...

todo lo que él dig̣a...

todo lo que yo diga...

Al mandato del valiente sha mash...

1. cría de un ave...

El aguila abrió su boca. diciendo a Etana:

¿for qué has venido?, dine ta"

Etana atrió su boca diciendo al àguila:

"fing igo mío, dane lo planto del nacimiento!

quita mi carga y produce para

mi un nombre,

\section{(v)}

(obverso )

....... el águila le miró

diciendo a ... a Etana:

"Tu eres en verdad Etana.

rey de los animales

Tú eres Etana....!

Levântame de $\in$ n medio de este pozo, 
dame....

y te daré descendencia humana Hasta la eternidad cantaré tus alabanzas!"

Etana dice estas polabras

a! gguil a:

"Si yo salvo tu vida...

y to llevo ruera del pozo ...

hasta remotos tiempos.

nosotros

$\ldots$

(reverso)

"Sobre mi ...

Desde el aranecer hesta ...

Cuando él salga de ...

Yo te dare la planta del nacimiento!"

Cuando Etana escichó ésto

llenó el frente del pozo

$\operatorname{con}=$

lueg̣o bajó dos...

... ncio ante ề. .

El águila no pudo subir desde el pozo.

El $\ldots$

$\because y \ldots$

Meyamente no puedo subir des de el pozo.

El bate sus alas.... .. ntia 
(obverso )

.. el aguila le miro

diciendo.... a Etane:

"Tu cres an verdad Etana,

el rey de los animales!

tu eres Etana....!

Levántame de en medio de este pozo.

dasme....

$y$ te deré descendencia humana

Hasta la eternidad cantar

tus a! abanzas!"

Etana dice estas palabras al sguila:

"Si yo salvo tu vida...

y te llevo fuera del pozo... hasta remotos tiempos,

nosotros... .....

... $\ldots$

\section{(VI)}

El águila abrió su boca, diciendo a Etna!

$$
\text { II }
$$

a la entracia de la puerta de Anu, Enlli y Ea

nosatios rendimos pleitesia,

a la entrada de la puerta de Sin, Shariash. Adad e Ishtar Yo abría la ...

Yo miro en torno mientras des ciendo... 
Ella estaba sentada en

centro dei fulgor.

... ... fue cargada

$\therefore \cdots, \cdots$

Un trono fue puesto...

a! pie del trono leones

Entonces despertó tenbl ando..."

El áquila dijo a él, a Etana:

"Migo mío, ahora se nos ha mostrado lel lunar de la plan ta dei nacimiento)!

Arriba, yo te llevarê al cielo de Anu!

Sobre mi pecho non tu pecho;

Sobre las plumas de mis alas, pon tó tus manos;

sobre mis costados, pon tá tus brazos".

Sobre su pecho, el puso su pecho;

Sobre las piunias de sus alas, él puso sus manos;

Sobre sus costados, el puso sus brazos:

Excesivamente grande era su carga!

Cuando lo hubo cargado una legua arriba,

el águila le dijo a él, a Etana:

"Mira amigo mío, como luce la tierra! 
Escudriña el mar a los costados de Ekui!

la tierra, en verdad, se ha vuel to una colina;

el mar se ha tornado en agua de un arroyo!"

Cuando lo hubo cargado una legua ariba.

[i] Eguil la le dijo a él, a Etana:

"litira, amigo mio, como luce la tierra!

la tierra..., ..."

Cuando lo hubo cargado una tercera legue arriba,

el águila le dijo a él, a Etana:

"pira, amigo mío, cómo luce la tie rra!

La tierra se ha tornado en zanja de jardinero!"

Después que habieron ascendido al Cielo de Anu,

hubieron llegado a las puertas de Anu, Fnljl y Ea,

el ăgui ĩa juntamente con Etana rin diercn pleitesía

... el alguila y Etana...

$0,0,000,000$

$\Leftrightarrow \ldots \ldots \ldots$

( VII )

Lá carga deja ...

El âguila de esté nodo le habla: 


\section{FRAGMENTOS ASIRIOS DIYERSOS}

AS. 4

Peno, a

Pero al león el la habia desde antiguo uncido a su vugo;

entonces sólo los fustigó con un lătigo y tendiéronso a su lado. ....... no había sido visible pues su rostro habia estedo vuel to con esplendor como

desde... hasta... esta cubierto con terrible luz (pu-ul-ha-ti)

terrible esplendor, del dios temido.....

Etana..... paralizado por el temor;

pero $€ l l \ldots \ldots, \ldots$ tenía en su mano

$\ldots \ldots, \ldots . .$. se lo dío diciendo:

"Oue ... continuamente...

que ... llueva abundancia..."
$1 "$

yo te llevare.

El águila... un pájaro

no hay

"Arriba, amigo mio,....

con Ishtar, la concubina...

al lado de Ishtar, la concubina...

Sobre mis costados pon tus brazos.

Sobre las plumas de mis olas, pon tú tus manos!"

Sobre sus costados, êl puso sus brazos.

Sobre las plumas de sus alas, él puso sus manos.

Cuando lo hubo cargado una lequa arriba:

"imigo mío, echa un vistazo, cómo luce la tierra!"

"De la tiorra...

y el ancho mar es como un reci piente".

Cuando io hubo cargado una segunda legua arriba:

"Atigo mío, echa un yistazo, como luce la tierra!"

"La tierra se ha tornado en un zurco...

y el ancho mar es como una cesta para pan"

Cuando lo hubo cargado una terce ra legua arriba:

"Amigo mío, echa un yistazo, como luce la tierra!" 
"pientras yo miraba en torno, la tierra desapareció,

y sobre el ancho mar, mis ojos no pudieron deleitarse!

Amigo mío, yo ascenderé al cielo!

Detente en tus huellas que... ..."

Ina lequa se precipito.

El águila bajaba y él a su lado...

Una segunda legua se precipitó.

El águil la bajaba y él a su lado...

tha tercera legua se precipitó.

El águi ia bajaba y sll a su lado...

Dentro de tres codos del suelo de Anu,

ei ăguila cayo, y ể a su lado.... ... el ăguila ha sido magullada; de Etena...

\section{Fragnentos asirios (? diversos}

\section{As . 1}

$00,00,000,000,0000$

. ............... ejecutó

Los pasajes que llevaban a su litero se habian estrechado, de modo que cuando un ataque al útero sobrevino, falló la al imentación sanguínea.

Entonces el fishipu, con un Kakku removio los huesos, pero El kakku por desgracia perforó la pared del atero cau sando hemorragia.

Para conservar la sangre, ella no acostumbraba a entrér al agua profunda. 
Pero la carne no se infectó,

y cuando la hemorragia que la ataco se hubo detenido, ella mejoró otra vez.

Posesiones, plata y oro ella no tenia.

Pero aunque la suegra de $\delta$ l hacía atractiva a la reina para él y el chambelán del bitanu... las mujeres del harem

su desco sólo se exaltaba por la hermosa Mudan.

$$
\text { As. } 2
$$

(obyerso)

"... el sostenia una planta

Bantenia el agua derramindose sobre ella,

....... que pudiera establecerse en su casa de el

A.jí llegó a su ciudad y a su casa".

Y a su esposa le habló de nuevo, a Etana:

"Mi señor, aquella planta era la planta del nacimiento!

$\ldots \ldots . .$. la tierra comenzó a abrirse

$\ldots, \ldots$ yo vi su crecimiento

$y$, cuando el fruto de la planta maduro, me alegré"

(reveso)

$\ldots, \ldots, \ldots$,

Etana le hablo a su mujer:

"Solo un... no respetarla éste ....

....... el mandato de los dioses ha salido

$\ldots \ldots . . . .$. ha llegado hasta nosotros

Asi Etana se resolvió a encontrar la planta...

El ........ a resolver el sueño 
As. 3

(obverso)

$n, \ldots, 0,0,0,0,0,0,0,0, \ldots$

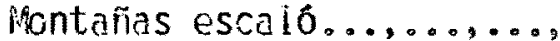

$\because \ldots$ la montaña "SI-EL-SÜELO-NO-SE-HUBIESE-ELEVADO"

la montaña ... alcanzo, a lo largo de su extensión

de los cedros el...

Ningû́n bloqueó su senda, el no detuvo

sus pasos:

pero la planta que le habria satisfecho su deseo,

no pudo encontrarla.

Así los dioses... llegaron al final, los años se cumplieron

(reverso)

$0,0, \ldots, \ldots, \ldots, \ldots, \ldots, 0, \ldots, \ldots, \ldots, \ldots$

$0, \ldots 0, \ldots, \ldots, \ldots, 0,0, \ldots, \ldots, 0, \ldots, \ldots, \ldots$

As. 5

(obverso)

Como león........

: Estaba vestido con...

Etana...

Con dolor.

"Llora por mí

. Despues quue él ... 


\section{(reverso)}

fund $0,0, \ldots, 0$

"El cetro... el fund amento de...

un cetro en verdad...

en riedio del trigo de este campo, sobre una estela escribe pst...

Su sangre pura se derrana sin cesar, empapados estaben sus vestidos, y como no eran posible ni ritos ni recitar encantamientos,...

Un Ishru llevo el cadiver de Etana a una sala del palacio;

cuande la posesión del utukku hubo ontrado, un principe del palacio que podía estar de pie ante el señor de la totalidad....:

"Que los sepultureros de sus miembros lo lleven a las llanuras,

a campo abierto...

que pastor y zagal, león y bestia salvaje vean su fantasma (etinmu).

Que no sea sepultado en el suelo que frecuenta la gente, macho o

hembra.

...... el suelo cultivado, propiedad del granjero...

Una tierra imirtu... suelo virgen... propiedad de........ 
ETANA - 2 - ORDEN LOEICO

a) Prologo

(Neo-Asirio) (635 A.C.) más elementos del Eabilonio Antiguo 1800 A.C.)

Los grandes Annunnaki que decretan el destino se sentaron intercambiando sus pareceres acerca de la tierra. Los que crearon las cuatro regiones, que establecieron las condiciones, todos los Igigi eran hostiles a la humanicad un tiempo fijo para la humanidad decretaron La gente oscura, en su totalidad, no habian establecido un rey. En aquellos días ninguna tiara habia sido ceñida, ni corona; tampoco un cetro habia sido engastado en lapislázuli. Las regiones (los santuarios) no habian sido creados en modo alguno. Los divinos siete contra el pueblo obstruyeron las puertas contra los colonos obstruyeron las puertas Los Igigi se habian marchado de la ciudad. Ishtar un pastor para el puebio un rey busca para la ciudad. Enlil inspecciona los distritos del cielo, Cetro, corona, tiara y cayado yacen depositados ante Anu en el cielo mientras continua el buscanco, no hay consejo para su gente. En la tierra un rey

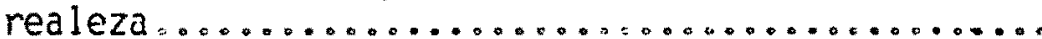

Entonces su corazón encitó Enlil. Los dioses. Entonces la realeza bajó del Cielo

NEO-ASIRIO II

b) Fábula

Ven, Jevantémonos remos jurado por el mundo inferior......" El juramento que juraron ante el valiente Shamast: 
"Al que transgrediere los vinculos de Shamash, que Shamash los entregue para mal al verdugo, Al que transgrediere los vinculos de Shamash. que la montaña le quite su paso, que el arma puntiaguda se dirija derecho a él, que la trampa, la maldición de Shamash, lo derribe y lo cace!"

Cuando hubieron jurado el juramento por el mundo inferior

se levantaron y subieron a la montaña,

Cada dla vigilaban ................

Cuando el águila ha cazado un buey salvaje 0 un asno salvaje,

la serpiente se alimenta, se retira, su cría se alimenta. Cuando la serpiente ha cazcido cabras montesas o gacelas, el águila se alimenta, se retira, su cria se alimenta. Cuando el saguila ha cazado ovejas salvajes o cabras salvajes:

la serpiente se alimenta, se retira, su cria se ai imenta. Cuando la serpiente ha cazado leopardos o tigres del campo. el aguila se al imenta. se retira, su cría se alimenta. El águila recibio su alimerito; su cría creciós en edad y estatura.

Cuando su cría hubo crecido en edad y estatura, el corazón del aguila tramó maldad;

y cuandio su corazón tramio maldad, resolvio en su mente devorar la cría de su amigo. El águila abrió su boca, diciendo a su cria:

"Ne comeré la cría de la serpiente; la serpiente........ subiré al cielo para poder hábitar alli, y descenderé a la copa del árbol a comer el fruto". El pequeño aguilucho, excelente en sabiduría, estas palabras a su padre dirigio:

"iko comas padre mio: la red de Shamash puede cogerte; la trampa la maldición de Shamash, puede derribarte y cazerte.

Al que transgrede los vínculos de Shamash, lo entregará Shamash a el para el mal al verdugo!" Pero él no las oyó, no atendi $\delta$ a las palabras de su hijo; descendis y devoró la cría de la serpiente. ....... a la mitad del día la serpiente llegó trayendo su carga de carne. A la entrada del nido arrójala a su cría.

Cuando la serpiente miro en derredor, su nido no estába; cuando se inclins, no lo vio. Con sus gärras, rasga el suelo; al polvo del nido cubre el cielo. 
(Babilonio Antiguo) A 2

"Oue la senda se pierda para el, que no encuentre

el camino!

Oue la montaña lo rechace de su paso!

que el arma puntiaguda se dirija derecho a el

Ellos se juraron este juramento mutuamerite.

Todos fueron concebidos, todos nacieron:

A la sombra del árbol estoraque, engendra la serpiente;

en su copa engendra el aguila.

Cuando la serpiente ha cazado un leopardo, un tigre.

el agulla se alimenta, su cría se alimenta.

Despues que su cria hubo crecico en edad y estatura,

sus alas hubieron adquirido.....................,

el águila tramo mieidad en su corazón:

"Hi cria he crecido en edad y porte,

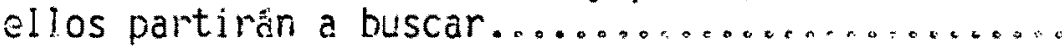

ellos buscarán la (s) planta (s)

Entonces yo devorare la cría de la serpiente...... ascenderé y en el cielo

yo habitaré $\ldots \ldots \ldots \ldots \ldots \ldots \ldots \ldots \ldots \ldots \ldots \ldots \ldots \ldots$

Quien hay que .............................?

El pequeño aguilucho, excelente en sabiduria,

al águila, su padre (estas) palabras dirigio:

"Fadre mílo...................................

.......... (resto del anverso destruido)....

(reverso)

La serpierte depositó su carga ante sus crías.

Hiro alrededor, sus crias no estaban

con sus garras resca el sueio:

el polvo del nido cubre al cielo.

İ serpiente................ llora

sus ligrimas fluyendo ante Sahamash:

En ti pongo mi confianza, valiente Shamash!

hi águila extend $\mathrm{mi}$ buena vaiuntad,

veneré y honré tu juramento.

no opuso maldad contina mi amigo

anora êl, su nido está entero. pero mi nido está destrozado

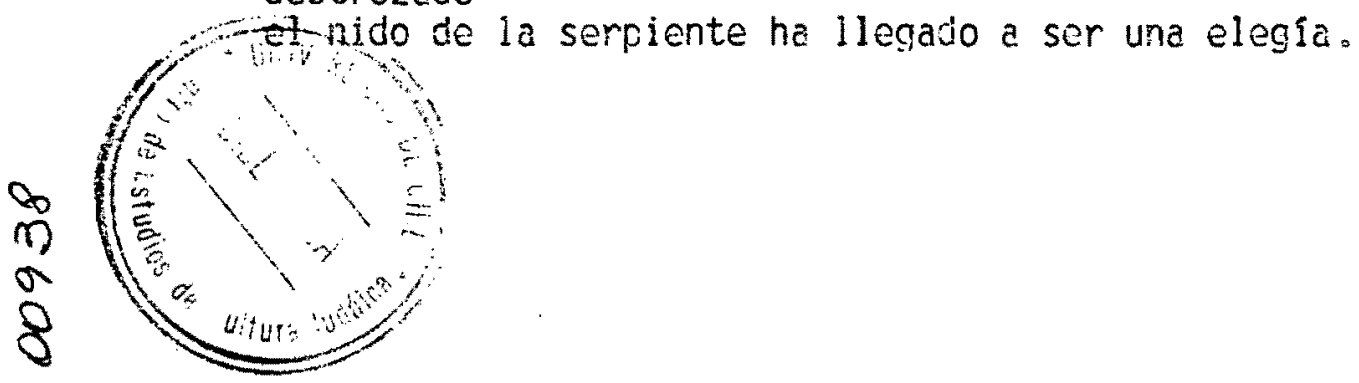


Sus aguiluchos están enteros, mis crias no esten: bajo y devoro mi descendencia.

Sabelo, on Sahmesh, que el persigue malriad

Tu red es el amplio campo.

tu trampa es el iejano cielo:

que el aguila no ascape de tu red.

el hechor de maldad y abominación

Que opone ialdad contra su amigo.

(NEo-Asirio) IIS

La serpiente yace $y$ llort.

sus legrimes fluyendo ante Shamesn:

"En ti pongo mi confianza, velienta Shamash!

Al squila cxtand $\mathrm{mi}$ buena voluntad.

Ahora mi nidio

mi nido esté destruido.............

destrozacias estan mis crias .......

bajo y jevoro mi descendencia.

Sebelo to. oh Snamash, la máldod que me ha hacho.

Ciertamente, of Shamash, tu red es la ancha tierra,

tu trampa es el lejano cielo:

Ge ei gauila no escape de tu red,

aquel milhection, $Z u$, que opone maldad contra su amigo".

Cuando Shamash oyo la queja de la serpiente,

Sharrash abrio su bocz, diciendo a la serpiente:

"Sique tu camino, cruza la montaña.

Yo atare para ti un buey saivaje:

fibre tu interior, rasga tu vientre.

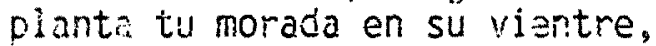

Toda clase de ave del cielo descenderá a devorar

la carne;

Ei ăguila descenders con ellos a devorar la carne

puesto que no conoce su infortunio.

Buscando ia suculenta carne. proceders cautelosamente, tentendo lo recondito del interior.

Cuando entre en el interior, cuggelo tí por sus alas

arranca sus alas, sus alones y sus garres.

desplanalo y tíralo dentro de un pozo.........

[ejjalo morir la muerte de hambre y sed!"

Ai mandato de! va!liente Shamash.

la serpiente fue y cruzo la montaña.

Cuando ia serpiente alcanzo al buey salvaje,

abrio su interior, rasgo su vientre, 
planto su morada en su vientre.

Toda clase de ave del Cielo dercondió a devorar la carne

Si el águila hubiese corrocido su inforiunio

no hubiera comido con las aves!

El águila abrio su boca, diciendo a su cria:

"Ven bajemos y devoremos la carne de este buey salvaje!"

El pequeño aguilucho excelente en sabiduría,

al águila su padre, estas palabras dirigio:

"Wo bajes padre mí! cuiza

dentro del buey salvaje acecha la serpiente!"

El aguila sin consultar con su corazón, dijo estas

palabras:

"Eajaré y coneré la carne del buey saIvaje!

¿Cómo podría la serpiente devorarme?"

El no las oyo, no atendió las palabras de su rijo.

Bajo y se poso sobre el bucy saivaje.

El agguila inspecciono la carne, exemino sus partes

delanteras y traseras

ivevamente inspeccionó la carne, examina sus partes

delanteras y traseras.

Procediendo cautelosamente, tienta lo recondito del interior.

Cuando entro en el interior, la serpiente lo cogio por

sus aias:

"i........."

El áquila abrio su boca, diciendo a la serpiente:

"Ten compasión de mí y ta haré un regaio de bodas

como a un novio!"

La serpiente abris su boca diciencio aj águila:

"Si te sue? to cómo respondere yo a Shamash en 10 al to?

tu castigo se tornaria contra mi

que deberia imponer castigo sobre ti!!"

Arrancó sus alas, sus alcnes y sus garrás,

10 desplumb y lo tirs dentro de un pozo,

diciendo: "fibrira su mucrte de hambre y sed!"

........ el aguila diariamente suplica a Shamash

"He de morir en el pozo,

Quien sabe como tu castigo fue impuesto sobre mi?

Sálvame la vida a mi, el aquila

y cantare tu nombre hasta la eternidad!"

Shamash abrió su boce, diciendo al águila:

"Tu eres malévolo y mie has of encido gravemente!

Lo aborrecido por los dioses y lo vedado, en

*erdad comiste

nungue has jurado, yo no iré a tí.

Fero he aquí, un hombre yo te eñviare, el tomará 
tu mano"

(Neo Asirio) (iV)

El águila abrio su boca, diciendo estas palabras a Shamash, su señor:

"1

aco

la cria de un ave.......

lo conduzca hacia acá.....

Todo lo que él diga........

todo lo que yo diga........

Al mandato del valiente Shamash.........

Ia cria de un ave........

El ảguila abrió su boca, diciendo a Etana:

"¿Por qué has venido? dime ta"

Etana abrio su bcica, diciendo al águila:

"Amigo mio dare la planta del nacimiento

quita mi carga y produce pera mi un nombre.

Nota: Aoul la fábula finaliza con el motivo de unión. A continuación comienza la Epopeya de Etana.

(Fragmentos Ásirios (?) Diversos

(Asirio i)

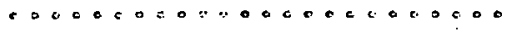

o................ ejecuto

Los pasajes que Ilevaban à su ́́tero se habían estrechado, de modo aue cuando un ataque al utero sobrevino, fallo la al imentación sanguínea. Entonces el ishipu, con un kakku removio los huesos, pero el kakku por desgracia perforó la pared del útero causarido hemorragia.

Fara conservar la sangre, ella no acostumbraba a entrar a! agua proíuncia.
} 
Pero la carne no se infecto,

y cuando la hemor ragia que la ataco se hubo detenido ella mejoró otra vez.

Posesiones, plata y oro ella no tenía.

Pero aunque la suegra de el hacía atractiva a la reina para el

$y \in 1$ chambelán del bitaru..... las mujeres del harem

su deseo sólo se exaltaba por la hermosa mudam.

\section{(Ascirio 2) \\ (obverso)}

".... el sostenia una planta......

riantenía el agua derramsndose sobre ella,

.... que pudiera establecerse en sul casa de él

Asi liego a su ciujad y a su case".

$Y$ a su esposa le habio de nuevo, a Etana:

"ili señor, aquella planta era la planta del nacimiento!

.......... la tierra comenzo a abrirse

......... yo vi su crecimiento

$y$, cuando el fruto de la planta maduro, me alegre"

(reverso)

Etana le hablo a su nujer:

"\$olo un..... no respetaría este........

.......... el mandato de ios dioses ha salido

........ ha liegado hasta nosotros

fisf Etana se resolvio a encontrar la planta......

El .......... a resolver el sueño

Hiquí se retomaría la continua i cion de la Tablilla Neo Asiria III.

Etana diariamente suplica a Shamash:

"Tu has consumido, oh Shamásh, mis mes gordas ovejas, 
bebiendose la tierra la sengie de inis corderos.

Yo he honrado los dinses y reverenciado a los espiritus

ias sacendotisas del oraculo han hecho lo necesario a mis of rendas;

los corderos con sus deguellos, nan hecho lo necesario a los dioses. On señor: que salga de tu boca:

otórgame la planta del nacimiento,

muéstrame ia planta del nacimiento,

quita mi carga y produce para mi un nombre!"

Shemash abrio su boca: diciendo a Etana:

"Sigue tu canino, cruza ia montaña;

al ver un pozo, examina su interior,

dentro de el vace un aguila;

el te mostrars la planta del nacimiento"

Al mandato del valiente Shumash.

Etana siguio su camino, cruzo la montaĩa;

cuando el vio el pozo, examino su interior:

dentro de el yacía un aguila

en la foima cono Shamash lo hatia hecho esperarlo.

(Heo Asirio) (5)

(obverso)

..... el aguila le miró

diciendo a Etana:

"Ta eres, en verdad Etana, el rey de los animáles!

Tú eros Etana......... !

Levántame de en medio de este pozo,

dame.......

$y$ te dare descendencia humana

Hasta la eternidad cantaré tus alabanzas!"

Etana dice estas paiabras al águila:

"Si yo salyo tu vida....

y te llevo fuera del pozo......

hasta remotos tiempos, nosotros

(reverso)

"Sobre mi ............ 
Desde el amanecer hasta.....

Cuando salga de............. n:

Vo te dare la planta del nacimiento!"

Cuando Etana escuchó esto.

l. lenó el frente del pozo con

Iuego bajo dos.....

........ndo ante éí.......

El Eguila no puóo salir del pozo.

El .......

$\ldots \ldots \ldots y=\ldots$

Muevamente no pudo subir desde el pozo.

El bate sus alas ......nte

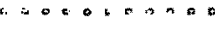

(Neo Asirio)(6)

El aguija abrio su toca, diciencio a Etana!

" "ja entrada de la puenta de Anu, Enlil y Ea

nosotios rendimos pleitesta.

a la entrada de la puerta de Sin. Shamash, fidad e ishtar

vo abri la .....

Yo niro en torno mieritras desciendo.....

Ella estaba seritada en el centiro del fulgor......

....... fue cargada.......

th trono fuc puesto

al pie de trono leones.......

Entonces desoerte temblancio...."

El áculia dijo a xíl, a Eana:

"fainigo mío, ahora se nos ha mostracio (el lugar de la planta del na cimiento)!

Arriba, yo te llevaré ai cieio de Anu!

Sobre rii pecho pon tú tu pecho:

Sobre las piunas de inis alas, pon tus manos;

Sobre mis costados, pon to tus brazos".

Sobre su pecho, él puso su pecho:

Sobre las plumas de sus ailas, él puso sus mianos:

Sobre sus costados, et puso sus brazos: "

Excesivanente grande era su carge!

Cuando lo hubo cargado una legua arriba,

el soguila le dijo a él, a Etana:

"firira amigo mí, como luce la tie:ra!

Escudriña el mar a los costados de Ekur!

La tierra en verdad se ha vueito una colina: 
el mar se ha tornado en agua de un arroyo!"

Cuando lo hubo cargado una segunda legua arriba, el tǵfula le dijo a él. a Etane:

"fíta. amigo mlo. cono luce le tieria!

la tierre......"

Cuando lo hubo cargacio una tercera legua arriba:

el águila le dijo a él, a Etana:

"Mira anigo mio, cono luce la tierris?

La tierra se ha tornado en zanja de Jardinero!"

Despues que hubieron ascendido al cielo de hu.

hubieron llegado a las nueries de Anu. Enlil y Ea,

el aguila juritemente con tana rindieron pleitesia

........ el Eguila y Etana.....

(Neo Asirio)

(7)

Lล้ cangen...

deja........

El aguila de este modo ie habla:

yo te ilievaré..

El águila... un pajaro...

no hay....

"Arriba, amigo mio...

con ishtar, la concubina.......

al lado de istitar, la concubina....

Sobre mis costados pon tus brazos.

Sobre las plumas de mis alas, pon tus manos!"

Sobre sus costados, tl pusc sus brazos

Sobre las plumas de sus alas. 61 puso sus manos.

Cuendo 10 hubo corgedo una lesuo arribe:

"Anigo mío, echa un vistazo, como luce la tierra!"

"De la tierra...

y el ancho mar como un recipiente".

Cuendo lo hujo cargado una segunda legue amiba:

"higo mio, echa un vistazo, cono luce la tierra!" 
"pientras yo miraba en torno. la tierra desaparecio. y sobre el ancho mar. mis ojos rio pucieron deleitarse! Ahino nio, ascendere al cielo! Detente en tus huellas que....." Uha legua se precipito. El Eguila bajaba $y$ El a su lado... Lira segunde legua se precipits. El cquila bejaba y él a su \ado.... Una tercera legue se precipito. El águila bajaba y el a su lado.... Dentro de tres codos del sueio de filu, el aguile cayo, y $\notin 1$ a su lacio... .... el águila he sido magullade; de Etana....

(Fragmentos Asirios Diversos)

(Asirio) (4)

Pua el lesn el lo habia desde artigno uncirio a su yugo;

entonces sojio los fustigo con un letigo y tendiéronse a su lado. .......... no habia sido visibie pues su rostro habia estado vual to con esplendor cono

desda... hasta..... esta cubierta con terribie luz (ru-ul-ia-ti) terribla espiendor: del dios temido...

Etana............. paralizado por el temor

pero ella........ tenta on su meno

a........... se lo dio diciendo:

"Que continuamente...

que.... Il ueva abundaricia...."

ASRPO (3)

(obverso)

Pontañas escaión

........ la montaria "SI-EL-SUELO-NO-SE-HUEIESE-ELEVADO" ia montaña .. . .alcanzó, a lo largo de su extensión de los cedros al.... Mingún obstículo biogueo su senda, el no detuvo sus pasos; pero la planta que le habréa satisfecho sus deseos: no pudo encontrario. 
Asf los dioses... liggaron al final, Ios años se cumolieron

(reverso)

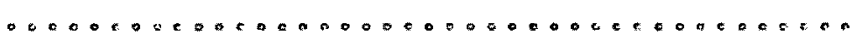

$\ldots \ldots$ en $\mathrm{l}$ os tendones yo $\ldots \ldots \ldots \ldots \ldots$

$\ldots \ldots \ldots$.

Yo....... una gacela macho, una cría de gacela yo....

Yo........ .. de Derro y.....

(Asirio)

(5)

(obverso)

como $1 \epsilon .5 n \ldots . . . .$.

Estaba vestido con....

[tana...

Con dolor...

"llorà por mi...

Despues de s]...

(reverso)

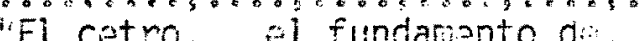

un cetro de verdad....

en medio dei trig̣o de este campo, sotre una estela escribe pst..."

Su sangra pura se derrama sin ceser, eimpapados estaban sus vestidos,

$y$ como no eran posibie ni ritos ni recitar encantamientos,....

Un ishru lievó el cadsver de Etana a una sala del palacio;

cuando la procesion del utukku hubo entrado, un principe del palacio que podía estar de pie ante el señor de la totalidad....:

"Que los sepultureros de sus miembros lo Ileven a las llanuras, a campo abierto...

que pastor y zagal, leôn y bestia salvaje vean su fantasma (etimu).

Que no sea sepultado en el suelo que frecuenta la gente, macho o hembra. ........ el suelo cultivado, propiedad del granjero....

Una tierra timirtu... sueio virgen.... propiedad de........ 


\section{ETANA - CRITICA HISTORICA}

El relato que hemos presentado tiene como personaje central a Etana, de quien la mitología mesopotámica nos informa oue "subio al ciejo en un aguila". Hecho sobre el cual la gliptica ha dejado también recuerdos.

Según los datos que proporciona el relato, Etana ha bría sido la persona subre la cual recayo la elección dé la diosa Ishtar que buscaba "un pastor para el pueblo.. ... y un rey para la ciudad".

La cinica referencia histarica que se tiene sobre es te personaje deriva de la "Lista de Reyes Sumerios".

Este documento -que data, aproximadamente, del $2 \%$ milenio-, recoge fuentes ciertamente mes antiguas, que son de notable valor si se quiere reconstituir la historia dinástica de los mesopotamios.

Se trata del primer intento de periodizar la historia. En él se consignan tamién una serie de dinastías reales pertenecientes a las diversas ciudades-estados su merias, el nombre de cada urio de los monarcos, los años de duracion de sus reinados $y$, algunas - a vecer brevisimas - notas sobre sus rechos más célebres.

Por sus caracteristicas, ei documento presenta cier tas dificultades: En lo cronologico, proporciona datos ciertamente demasiado fabulosos en cuanto al numero de años que habría durado el reinado de cada uno de los reyes.

En lo que respecta a la secuencia dinastica hereditaria, a juicio de alguros autores, quienes la copiaron habrian adoptado la corvención de que las dinastias se habrian sucedido una tras otra, cuando de hecho, muchas de ellas debieron haber sido contemporáneas.

Ho obstante las dificultades estipuladas en el pe rrafo anterior, cabe reiterar que -junto con el texto li terario objeto de este estudio- la lista es el anico documerto en que se menciora a Etana.

Acorde al documento en cuestion, la historia monerquica de liesopotamia conocio dos grandes pericdos, sepa- 
rados ambos por un acontecimiento singular, cual es la existencia del "Diluvio universal".

Es asi como la soberania, "don divino", descendio del cialo en dos onortunidades diferentes.

La primera de ellas, antes del Diluvio, teniendo como primer centro la ciludad de Eridu.

En este periodo "antidiluviano" hubo cinco dinastías, cada una de ellas en una ciudad diferente, ellas son: En Eridú, Ead Tíriba, en larak, en Sippar y en Shurrupak. El rúmero de monarcas alve reineron fue de ocho y la suma de esos años de reinado totalizaban 241.000 años.

La segunia vez que la rezleza descendio, acontecio "despues que el Diluvio hubo barrido.." y entonces "... ia soberania estuyo en Kish".

Según esta fuente, Etana -nuestro rey-pastor- ha bria sido el decimo rey de la dinastía postdiluviana osentada en la ciudad de kish. El recho aperece consig nado de la siguiente manera:

"..... Etana, pastor, el oue ascendio al cielo, consolits a todos los parses, llegó a ser rey

y goberno 1560 años..."

Aunque escueta, la cita es de suma importancia para la reconstitucion historica: Nos señala que en un tiempo -presumiblemente a comienzos del 30 milenio- la ciudad de Kish habria cietentado la supremacia politica-religiosa en toda Sumeria. Esta preeminencia la habría logrado durante el reinado de Etana, quien habria gobernado ener gicamente destacendose por su habilidad politica que le permitio ejercer una influencia unificadora en el destino de las ciudades.estados de la época. Esta influencia la habria ejercido, además, por espacio de más de un milenio y medio.

Al comienzo señalabamos que otra referencia sobre este personaje se obtiene del arte. 
En efecto, la gliptica viene a presentarnos mayores detalles. So trata de un pequeño sello akkadico-de la segunda mitad del 39 milenjo-de aproximadamente $4 \times 7$ cms. en el que se evidencia, con gran claridad plástica, una representación de la leyenoia.

Sobre este sello, transcribimos a continuacion dos lecturas posibles: la de Sir Leonard Woulley y la de Andre Parrot. Con posterioridad a Ellos, daremos la nuestra, producto de una lectura minuciosa.

rior (3) señala:

L. HOOLLEY en su libro Piesopotamia yel Asia Ante-

"En una representación de la jeyenda de Etana vemos a un pastor de cabras, que hace salir del establo a sus animales, en el centro de la escena el aguila lleva a Etira al cielo. Un scgundo pastor que protege su vista con Ia manc, le contempia tristemente. Dos perros senta cos ladran a la luna; un hombre se va a propagar el men= saje y otra figura, sentada ante una hilera de vasijas, simboliza seguramente la casa de cempo".

A. PARROT en su libro srimer (4) ser̃ala: "Indudablemente podemos reconocer una representacion dei mito de Etana, en $\in$ se pastor subido al empireo por un águila poderosa. Resulta casi conmovedor el ver con que infantil fescura esta relotado. Los perros abandonados, levontan la cabeza al cieio, como estupefactos, a causa de esa as cención; pero ide cucintas escenas no liegamos a reccger el mensaje".

Queremos destacar el hecho de que en ninguna de las dos lecturas aquí presentadas se ha hecho un detalle de cada uno de los elementos que en $\in l$ sello se encuentrán.

Ciertamente, como dice Parrot, de muchas escenas "no llegamos a conocer el mensaje", algo de eso ocurre también en este sello con algunos elementos que no podemos defirir a ciencia cierta y que, si están presentes es porque tienen su propio significado. Sin embargo, nuestra lectura difiere un tanto de las anteriores.

Coincidimos en que se trata de la reproduccion de un sello relativo al mito de Ftana. En $\mathrm{el}$ cabe diferenciar dos mundos: el cotidiano representado en el costado izquierdo, donde se encuentra el "pastor" HACIENDO SALIR 
A SUS ANIMALES DEL ESTABLO", y el mundo mitico: en el costado derecho donde vemos a Etana montando en el aguila, y rodeado de elemeritos pertenecientes al relato.

El paso de transicion, o de unión entre ambos mundos, es la presencia de ese pastor, ubicado en el centro de la escena, en una actitud típica de adoracion.

Creemos, que una lectura posible, es el considerar la presencia de un solo personaje: el pastor Etana, en tres momentos diferentes:

a) Ftana, rey pastor, "el rey de los animales", con un cayado en su brazo derecho, lieva a rus animales al campo. Esta escena de la vida cotidiana esta reforza da por la escena del mismo lado, en la parte superioŕ, donde encontramos una escena de campo. Un individuo se halla sentado ante 10 que puede ser, probablemente, una vasija de cerámica: un alrarero modelando una vasija (?).

En al otro extremo superior, un segundo individuo, en una posición a simple vista un tarito insolita, pero que pensamos está en cuclillas, continúa haciendo cir culos (?). Entre ambas figuras, ura estantería eñ la que se han ido colocando las vasijas, y la serie de esferas que al parecer pueden imputarse a la ac ción ejecutada por el personaje ubicado en el angulo superior centrico últimamente descritc.

b) En la parte central: Etana, en actitud de adoración. A su extrema izquierda algo cue pudiera ser una vasija (?) que contendria granos (?), en calidad de ofrenda (?), o tal vez algún liquido destinado a liba ción (?). En su costado derecho, un elemento que no nos atrevemos a leer, por carecer de juicio suficientes.

c) La tercera escena: el mundo mitico. Nos trae el re cuerdo de algunos pasajes ciel relato del viaje de Etana: montado en los lomos del squila que, con las alas extendidas, vuela hacia $\in$ l cielo, mientras le relata su sueño (noten la cabeza del águila con su pico abier to).

Con seguridad y a han rendido pleitesía ante la puerta de finu, Ea y Enlil y se dirigen a la puerta de Sin, Shamash, Yshtar y Adad. Nótese los símbolos de Sin, la luna y shamash el sol, a ambos iados, en la parte superior, a la altura de las cabezas del aguila $y$ de Etana. 
En el ángulo izquierdo superior de la escena, se ve a una figura femenina sentada: Ishtar (?). El relato dice que al abrir la segunda puerta "ella estaba sentada en el centro del fulgor..." (Cfr. Neo-asirio VI), y lineas despuess se sigue, (siempre relatando el agui la su sueño a Etana): "un trono fue puesto..... al pie del trono leores...". Ante Esto, queremos llamar la atencion a la escena que se ha esculpido justa mente debajo del águila en vuelo: allí, en un tamañó un tanto menor que el resto, se evidencia la figura

de una persona, de sexo femenino con los brazos un tanto extendidos, y flanoueada por dos animajes, en cuyas figuras rosotros reconocemos a dos leones.

Siendo así creemos que allli se representa esa parte del mito.

En el angulo inferior derecho, inmediatamente erriba de la figura de uno de los animales, se ve otra figura: cotra divinidad, quizas fidad, para completar el cuarteto de divinidades de la segunda puerta? (no lo sabemos). Inmediatamente sobre esa figura hay algo que parece ser una cesta. En esa îigura tambiên creemos reconocer otro elemento del mito. Aquel momen to del vuelo, cuardo han sobrepasado la segunda legua arriba y el águila inquiere a Etane: "finigo mín, echa un vistazo, como luce la tierra". "la tierra se ha tornado en un surco,.. y el ancho mar es como una ces ta para pan" (Cfr. tablilla heo-asiria VII)。

Honestamente pensamos que no es tan ilugico el in tentar leer este sello en forma de "comics" por cuanto ya se posee antecedentes de un caso similar y aunque no se trata de un selio, no es menos cierto que las escenas del Estandarte de ur, que ilustran la parte belica, pue den tener, a juicio de los entendidos dos lecturas posi= bles: la de cuatro carros diferentes, o bien, al igual que un "comic" tratarse de un solo carro en cuatro momentos diferentes". 
IV. ETANA Y EL ANTIGUO TESTAMENTO: ESTUDIO COMPARATIVO

En las paginas siguientes intentaremos un estudio en tre los textos del Antiguo Testamento y la épica de Eta= na. Esta comparacion se hara a nivel lexical, de motivos y situaciones.

i. Comparación a nivel lexical.

Tratar de establecer coincidencias lexicales entre dos relatos diferentes es una labor ardua. Tanto más si, como en el presente casa, no se cuerita con ios relatos es critos en su lengata orighinal debe trabajarse a base de tráducciones.

No obstante ello, y pese a las limitaciones de len gauje que afectan nuestra labor, trabajaremos en dos rive les.

El primero, con la intencion de entregar una serie de figuras literarias o palabras usadas en el texto mesopotánico, muchas de las cuales aparecen en la piblia,cons tituyen terminos que tenierico un significado icientico, en ia practica pueden simbclizer esperitus diferentes.

El secundo nivel es la contrastación -solo a modo de ejempio y por 10 tonto no exhaustivo- de aijurias frases del relato mesopotánico que encuentran lin paralelo o seme janza lingüsstica en algunos de los textos.

les por separado.

Veamos, a continuación, cada uno de estos dos nive-

a) Aclaraciones sobre el vocabulario usado en ambos relatos.

De una primera lectura rápida del texto de Etana, re saltan ciertas palabras que a no dudar, son empleadas al = guna vez en los textos bíblicos, ellas son: "águila" "ce tro", "corona", "descendencia", "D:s", "juramento", "nom= bre", "pastor", "planta del nacimiento", "rey", "sabidu ria", "serpiente" y "tiara".

iremus viendo, pues, cada una de ellas en detalle y efectuando su contrastación significante. 
Relato Biblico (i.T.)

En la Biblia, las costumbres del Éguila sirven para efec tuar variadis comparaciones. Asi es como el hebito de hacer su nido en las eitures simbolizá la soberbia de Edom (Job 39:27; Jer. is:15; Abd. 4). La rapidez de su vielo re presenta la ligereza de un ejercito para invadir pueblos extraños como koab y Econ (Job 9:26; 25::23; Lm 4:13; Jer 48:40; 49:22) o el propio pueblo Ge Isroel (Dt 28:49; Jer. 4:13; CS. 8:1; Hab. $1: 3$ ).

La forma como esta ave enseña a volar a su cria simboliza - ilustra el cuidado anoroso de D's pera su pueblo (Ex.19: $4,5 y^{\prime}$ ot $\left.32: 11\right)$.

\section{Relato Hesopot.5mico}

Al parecer, en la literatura mesopotamica el aguila no gozaba de gran estimación. En el texto de Etana, en la parte ce la fabula, represerita a un animal perverso que premeditademente transgrade un juromento. A raíz de su actuacion es castigada por shanasn. dios de la justicia. Sin embar go, solapadamente y haciendo gala de gran astucia, busca conseguir el perdón de la serpiente prineroy después de Shariasin.

En el texto se la denomina "aquel malhechor zu".

En otros textos es mencionada también de ese mismo modo,en especial, en el hito de Inanna y el arool huluppu, y en el propio mito de $2 u$, que narra como esta "divinidad pajaro" robó las tabilillas del destino (Cfr. JoB.Pritchard, ÂHET PD. $(11-1(3)$.

\section{CETPO}

Relato Biblico (A.T.)

El cetro es la vara que simboliza la autoridad de un legis lador. Generalmente lisada por los reyes surgen de la evo 
lución del significato dol basión del anciano, teniendose como simbolo de la sabiduría y soberania del rey (los lar gos) o como evolucion de un arma primitiva, como el sim = bolo del poder conguistador del rey (los cortos).

Relato Nesopotámico

En el texto de Etana el cayado al igual que la tiara y la corona, son usados en señal de simbolos de la realeza y la autoridad.

Cosona

Pelato giblico (A. T.)

Simbolo distintivo de nobleza, realeza o autoridad,que se lieva sobre la cabeza. En la época del A. T. ten ia un sen tido simbolico. Ast es como la de bavid y sus descendieñ tes representaba el raino asegurado por un pacto con d'ś reino que podia perterse por apcstasía (sal $89: 38,39$, cp $2(: 3)$

Relato Mescpotsmico

Acs, al jgual que "tiara" es usado como s?mbolo distintivo de realeza o autoridad.

DESCEROENCIA (5)

Relato Biblico $(A, T$.

La obtención de la descendencia esta expresada en la Ei blia en función de la tormación y perpetuación de un pueblo. 
Relato hopotamico

La obtención de ia descendencia está expresada en el relato mesopotamico en funcien de la legitimación cie la monarquia dinástica.

Dis

Pelato Biflico (fi. T.)

ń ciferencia de otros puebios de la época, el pueblo hebreo es monoteista.

D's es ui ser poderoso que ejerce su dominio como dueño y señor de su puebio y de todo el universo, y lo hace con amor y justicia.

La creeicicia en un D's unico estáa expresada en el texto błbijco en ia que constituye la declaracion de fe del mono tâsmo hebreo "Sin má Israel, A' eloheinu, A" ejad".

Relato Hesopotsinico

El hombre mespootámico ss por excelencia un ser poilteista. Sus dioses estann estrechamente ligacios a los grandes fenome nos de ia naturaleza, la fertilidad y ios fentmenos atmos = fericos.

El panteon mesopotamico estaba organizacio al modo de ia familia humana: la diyinidad principal era el padre de los otros dioses.

En el texto vemos como se habla de la Asamblea de dioses, los grandes ániunnaki.

JURAMERTO

Relato Biblico (A. T.)

E] juiamento es entendido, en general, como una forma de mialdicisn. La persone que presta juramento en el santuario 
pide a D's cue la aniquile si falta a la verdad. La formula

"Tán cierto como que D's vio" ( $1 \mathrm{~S} .20: 12$ ) supone la siguien te conclusion: "recibire castigo si miento".

Se sabia que si despues de expresado el juramento se habia jurado en vano, sobre el transgresor recaía un poder grande y misterioso del que no podía escapar.

Relato Piesopotemico

El juramento esta entendido en este texto como un pacto que compromete la voluntad $y \in$ ? honor de los pactantes.

duien lo transgrecie se verá castigado por los dioses, como efectivamente ácontece.

PASTOR

Felato Eiblico (A. T.)

Nombre dado al encargado de cuidar ovejas, u hombres en sen tido figurado. La Eibila en parte procede de una cultura ri ral, pastoril y campestre. En tal sentido, b's es por excé lencia el "Fastor de isreel" (Sal 80:4; 23:4; Jer.3̂:10). fisi también los reyes, goberradores y lideres eran considerados pastores y conc tales debian responsabilizarse por el bienestar de su pueblo.

Relato Mesopotámico

Creemos que en Etana, el significado de pastor debe enten derse en anbos sentidos: en $\in$ l figurativo, como pastor de hombres, bien lo señala el texto necasirio cuancio dice "Ishtar un pastor para $\in$ l ruebio..." y en el sentido estric to dei têrmino, cono pastor de animales. fisi parece despreñ derse del obverso de la tablilia y del reíto neoasirio cuando el águila exclana: "Ta eres, en verciad, Etana, el rey de los animales!". 


\section{PLANTA DEL NACIMIENTO}

Relato Bfblico $\left(A_{0} T_{0}\right)$

Vimos como, para los hebreos, siendo un pueblo de extracción oriental, la descendencia es bendición diviria.

En relacion a este tópico, en la Riblia se menciona la "mandragora" planta a la cual se le atribuia supersticiosamente la virtud de hacer fecundas a las mujeres esteriles. Sils ral ces, de formas curiosas, dieron origen a la creencia de qué posesa cuailidades afrodisiacas o que aseguraba la concepción (Gn $30:\{4-16 ;$ Cnt $7: 13)$.

Relato Mesopotámico

En el texto que nos ocupa, se menciona la "planta del nacjmiento" en relación a un sueño que Mudam - la favorita de Eta na- le relata a su amado, quien al parecer y según otro frag rento, habria tenido problemas de origen o caracter aborti yo: "ivi señor, aquella fianta era la planta del naciniento!

(Cfr. Fragmento asirio 2 , obverso).

Obviamente el problema de la "cescendencia" es importante en el relato ya que era necesaria fara consolidar la monarquia hereditaria.

Tal cono lo señalaramos al referirnos a la serpiente, un autor aduce que la "pianta del nacimiento" que Etana busca es.ta custodiada por un aguila. Suponemos que se refiere al "árbol estoraque" donde engendran ei fglisia y tambiên la ser piente.

El Erbol estoraque es un arbol estiracáceo, de flores blan cas y fruto elipsoidal, algo carnoso, de cuyo tronco se obtiene un bálsamo muy oloroso, usado tanto en perfumería como en Redicina. Desafortunadamente ignoramos si al igual que la manorkgora, esta relacionada con cualidades afrodisiacas. como quiera que sea, no encontramos ningan fragmento en el que el autor citado pudiese baserse para su aseveracion.

PEALEZA (REY), Concepto de

Relato BIblico (A. T.)

El establecimiento de la monárqusa rebrea difiere un tanto 
del concepto mesopotámico.

El verdadero rey es D's. El rey debe presentarse ante su pueblo como un ejemplo de obediencia a la voluntad de D's, declarada por boca de un servidor, el profeta, y así ayu ourlo a llevar adelante a la mision que D's le habia encomendado. La monargula heorea nace de una alianza entre las tribus quienes exigen un rey, para as s senejarse a los otros puebios.

\section{Relato hesopotámico}

En Presopotamia en un conienzo la realeza es una energencia oportuna, instituida ad hoc $y$ no visualizada como necesariamente permanente; fiero las continuas y prolongadas luchas entre ias ciudaces-estadios oiginaron el nacimiento de la monarqusa hereditaria y dinestica.

En ivesopotamia, a diferencia de Egipto, se tione concien cia de la limitacion del rey ante los dioses. Solo excep cionalmente un rey mesopotánico pieclems su deificaciún, es el caso de Naram Sin. Por lo genera!, ios royes son en tronizados por la jivinidá.

SABIOURIA

Relato Esblico (A.T.)

La sabiduríe tiene aspectos norales y religiosos, y se pre senta siempre como lo opuesto a la maldad ( $\mathrm{Pr} 10: 23$ ) empie za por dar a d's el lugar prominente en la vida y se ex=tiende a toda actividad (Pr $1: 7 ; 9: 10$ ). Los significados que tiene en la Biblia son todos de un sentido práctico: significa, entre otros, destreza técnica (Ex $34: 3,6 ; E z$ $27: 8$ ), aptitud en artes o sagacidad on los negocios (Job 12:2,12); ciencia mágica (Gn a $1: 8) ;$ discerniriento para aconsejar (2 Sa 13:3); prudencia para gobernar (1 R $3: 28$ ). Consiste en la aplicación no selo de la cordura en la vida diaria y decisiones eticas, sino todo lo que uno sabe apli carlo a lo que uno hace a fin de obtener un buen vivir. 


\section{Relato Mesopotsmico}

En el texto de Etana gcsecn sabidula significa "poseer dis cernimiento para aconsejar". En la fabula de la serpiente y el aguila, es el aguilucho "excelente en sabiouría" quien aconseja a su padre sobre el nodo correcto de actuar: "No comas padre mío; ila red de Shamash pueda cogerte, la trampa ia maldicion de sinamash puede derribarte y cazarte!" (neoasirio. II). El aguila hizo caso omiso de los consejos de su hijo y, como era cable esperar, recibio el castigo.

SERPIENTE

Relato Biolico (A.T.)

En la Eiblia hay siete paiabras para denominar diferentes tipos de serpientes dificiles de identificar en la terminología zoolúgica moderna.

Se mencionan frecuentemente las caracteristicas más comu nes de ellas: su veneno (ifm 21:6; Dt. 32:64: Sal 58:4; $\mathrm{Pr}$ $23: 32$ ), su posibilidad de encantarla (Ec $10: 11$ ), su vivienoa y sus hábitos (Gn 49:17, Pr 30:19; Ec. 10:E; is 59:5) y

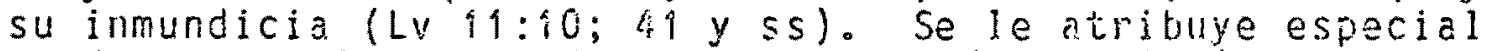
prudencia y algunos poderes curativos (nin 21:4-9), aunque se señala que el poder provenía de o's. Tanbien es usada como figura de distintas realidades: las naciones se presen tan como serpientes lanisendo el folvo ante el D's de lisrae (M 7:17). Representa a los malvados, a los enemigos de Is rael en general (Egipto, Asiria, entre otros); a jos efec tos del vino, al peligro, etc. etc.

\section{Relato kiesopotámico}

Al modo negativo como tratan a la serpiente en los textos biblicos se opone el relato mesopotamico. En la parte de la fabula del Mito de Etana es prescintada como un animaí capaz de convivir en armonia con otro, marced a l juramento de la amistad. Cuando el juranento es transgredido no toma vengan za por si misma, se vuelve hacia Shamash clamando justicia. En el Cercano oriente este animal esta vinculado, al pare cer a ritos mistericos relacionacios con la fertilidad. Es 
muy usada en la decoracior coramica y en la decoración de los vasos (Cir. Vaso de Gudea y de Eittcmena). En lo relati vo a la fertilidad ver las estatuillas de la época de ellubaid con sus facies de ofidio y cuerpo muy semejante.

En relación tambión a la fertilidad, cabe cestacar que uno de los autores consultados asegura que la pianta del nacimiento que busca el pastor Etana no es otra cosa que el ar bol estoraque, árbol al pie del cual "engendra la serpieñ te" (Cfr. Asirio Medio I).

TIARA

Relato Biblico (A.T.)

Nombre dado a un gorro alto de lino fino y de forma cóni ca, usado por los sacerdotes como sigho de dignidad sacerdotal (Ex 28:40, 29:9; 38:28; LV 8:13).

Relato Mesopotsmico

En el texto mesopotánico esta dado como uns cie los simbo los de la realeza o autoridad.

De 10 expresato en esta cerminologio comparada pademos señalar que, salvo honrosas excepciones, no hay mucha variacion en el significado del vocablo empieado.

Aś es como cetro, tiara, corona y cayado tienen igual signiricado: se emplean cumo simbclos de reaieza o autoricad. El]o no es de extrafiar si, como bien sabemos, los hebreos pidieron un rey para semejarse a los deinas pue blos.

La planta del nacimiento, por ia significación que te nía en el mundo orierital la descendencia, es también un elemento común en ambos mundos. Uifieren si en e! significado que tiene para ellos la obtención de "un nombre".

En el mundo mesopotamico Etená anda tras la procura de un nombre para asegurar la monarqua que debiera ser 
dinastica; en ei mundo ốblico, sa busca lo descendencia con la finalidad de preservar el pueblo.

ctra diferencia notable es en relación a la significacion de los animales, águila y serpiente.

b) Coincidencias Lexicales

Veremos ahora el grupo de frases seleccionadas -a modo de ejemplo-que permiten realizar un paraleio con frases encontradás en los textos biblicos.

Texto Mesonotímico.

- "En tí pongo mi confianza, valient? Shariash"

(Babilcinio Antiguo, A 2, re verso)
Texto Bibilico

- "En ti confiarán los que conocen tu nonbre" (Sel 9:10) (8)

- "Guardarie D's que en ti he confiado" (Säl $16: 10$ )

- "o's mio, en tí confró" (Sal 25:2) (9)

- "En ti, on "A", he confiado" (Sal $3 \hat{i}: \hat{i})$

- "has yo en ti confío, oh D's, digo: Tú eres mi o's" (Sal 31:14) (10)

- "A", D's mío, en tí he confiado" (Sal. $7: 1$ )

- "To guardarás en conpleta paz a aquèl cuyo pensamiento en ti perseverá, porque en ti ha confiado" (Isa 26:3)

- "El corazón del sguila trams malcad" (fivoasirio)

- "El águila trams maldaj en su - "He aqui el impio concibio maldad" corazon" (del Babilonio ariti guo A 2) 
Texto Nesopotámico

Texto Riblico

- "Que la senda se pienda para ell, - Milialito serás tú en la ciudad, que no encuentre el camino" (del Babilonio antigus $A 2$ ) $y$ mádito en el campo, maldita tu cancsta y tu artesa de amasar Pialdito serás en tu entrar, $y$ maldito en tu salir" (Di $28: 16-\{9$ )

- Madito al que hiriere a su projimo ocultamente" (Di 27:24)

- "Asceinderé y en El cielo..." (Babil. antiguo fic, anverso)

- "Subiré al cielo para poder habitar allf" (Neoasirio)

- "Subiré al cielo, en lo alto..." (Isa $14: 13$ ) (11)

- "Padre mío......"

. "Padre mío, pariro míc...."

(Babilonic antiguo, A2, anver

- "Cue el águila no escape de tu red" (del neoasinio)
- "iCastígalo, Oh D's!" (Sal 5:10)

- "Levantate, on A", en tu ira! álzate en contra de la ruria de mis angustiodores..."

\section{3}

- "Al que transgrede los víncu Ios de Shamash, lo entregars Shamast a el para mal al verdugo" (del neoasirio)
- "iCastigalo, oh D's. Caigan por sus mismos consejos; por la multitud de sas transgrecionas échalos fuera, poingue se rebelaron contra tí!" ) Sal $5: 10$ ) 
- "Tiralo dentro de un pozo" (del neoasirio III)
- "Y le echaron en el foso..." (Dan 6:16)

- "Y fueron echados en el foso..." (Dan 6:16)

\section{3}

- "Ten compasién de mí y te haré un regalo de bodas como a un novio"

$$
\text { (del necasirio III) }
$$

- "Amigo mio, deme la pianta del nacimiento"
- "... y tenga compasión de tí" (Deut 13:17)

- "oh vosotiros mis amigos, tened compásión de mi!"

- "Te ruego me des de las mondragoras de tu hijo".

De la lectura comparativa de la "fraseologia" aqug consig nada, cabo destacar que:

a) En algunos casos muy señalajos, la coincidencia lexical se adecúc palabra a palabia.

b) En otros casos, la diferencia es de matiz muy dabil: ra dica en las formas verbales y el pronombre usado, aungue mantiene la intención.

c) Con mayor frecuencia nos hemos encontrado con una fra seología que si bien es cierto difiere en su forma lexi cal, encierra una intención similar a la que, a simplevista, se evidencia en cl texto mesopotámico. Tal es el caso, por ejemplo, de las maldiciones.

d) Hay que destacar, como a itamerte significativo, el he cho de que el mayor número de similitudes encontradas en el Antiguo Testamento, pertenecen al libro de Sal mos. Creemos que ello no es de extrañar por cuanto anbos iextos pertenecerian a un tipo de iiteratura reli giosa, cuya forma de expresion sería común a los puerios del Antiguo oriente (13). 
2. Comparacion a nivel de situaciones y motivos

También resulta de gran interés establecer comparaciones en posibles situaciones o motivos que se presentan tanto en Etana como en el Antiguo Tastamento.

a) Un "fruto" prohibido

Enpezaremos por el texto de Etara, Jonde en el relato babilonio antiguo, täblilla $V$, relata:

"Te has portado perversinente................

lo aborrec: do por los dioses y lo vedado en verdad coniste"

La situación qua se denuncia, es el hecho de haber comido algo que los dioses aborrecen.

Fareciera ser que se enfatizan más en el motivo que en la situación. Por esta razón más tarde el águila recibirá el castigo que se merece.

En el Antiquo Testamento puede decirse que hay alguna similitud en el relato de la transeresion de Eva y Adán al comer del fruto prohibido: Fruto que crecia en un árbol determinado y que estaba destinado a proporcionar a quien comiese de el un cierto tipo de conociniento del "mal" en con traste con el "bien". A este arbol, junto con el srbol de lä vida (Hajayim), se les atribuyen derivaciones espirituales.

En Gén. 2:17 encontranos el "Erbol de la ciencia del bien y del mal". Frente al cual habsa una muy precisa limi tación que, de todos modes, perinitya el uso del libre albe= drio: Quien estuviera frente a $\hat{\epsilon} l$ y su fruto lo atrayera, tenía la posibilidad de decidir.

"...el día que de El comiéreis". La prohibición es tate acompañada de un severo castigo: la muerte. Algunos han pensado que las palabras que expresan el castigo, reque rían su ejecución en el misno día en que se violara la orden. Veri una discrepancia seria entre el anuncio y su cum plimiento. Sin embargo, el anuncio divino se puede expresar literalmente: "... muriendo moriras" lo que significa que en ese preciso memento se pronunciaría la sentencia a la fàta. 
Antes de Gen. 3:6, Adán pocía estar seguro de la inmor talidad que le oturgúa el árbol de la vida, as también, cespues era segura su muerte. El relato nos ubica, pues, an te una situación que, de hecho, provoca un castigo ineilidi= ble.

En ambas situaciones, en el relato mitico de Etana como en el del huerio de Edến se da el caso que alguien come 10 prohibicio, y en ambss casos el castigo vienc como consecuericia, salvando las diferencias en cuanto a lo comido: los hijos de, o el hijo de la serpiente en Etana, y, el fru to de un árbol en la Eiblia.

\section{D) Busqueda de descendericia}

En el texto de Etana la basqueda de la pianta del naci miento, estaba motivada por la incapacidad de la hermosa mú dam para piroveer ia ansiada descendencia. Ella que rio es "la reina", compite con las mujeres del harem, llevandose la preferencia.

Etana hace lo imposible con tal de obtener la planta $y$ de este modo lograr que pudan ie de el ansiado heredero.

Este relato tiene paraielos con algunos textos bibii cos que, si bien estan presentados en torno al tema de la descendencia de una determinada mujer preferida, no existe en ellos -fuera del motivo semejante- una situacion piena inente identica.

En los casos conocidos se busca la "bendición" que un hijo significa ya que como sabemios, en ambos ambientes la no-descendencia representaba algo más que una simple y trís te frustación.

Veamos por ejemplo a fibraham y Sara, para quienes, el anuncio "Haré de tí una ración graride" (Gn. $12: 2$ ) expresa un senticio de compensación para quienes por fe, han abandonado su pais de origen.

En Gn 12:7 leemos: "A tu desceridencia daré yo...". Todo el mensaje se compone de cinco palatras en hebreo, su brevedad no tiene relación con la importancia ni con el va- 
lor de la promesa. Se ricesitaba fe para llegar a creer que los cananeos, ahora organizados en ciudades poderosamente fortificadas, serian desposeidos y su tierra dada a un anciano sin hijos. La evidente improbabilidad de la realizacion de lina promesa tal, la convertia en una dificil prueba.

En Gn. 15:2, la frase: "Ando sin Hijo", expresa el te mor de Abraham ante el hecho de que carecía de un heredero ... y siendo así entendemos que la frase "el majorcomo de mi casa" es una queja, ante la posibilidad de tener que en tregar su heredad al damasceno Eliecer.

El pasaje anterior se hace comprensible gracias a los registros mesopotámicos -particularmenite los de los tiempos patriarcales de la ciudad de kuzi-. En ellos se mues tra que una pareja rica que no tuviera hijos, podia adoptar a uno de sus esclavos, quien devenia en heredero de toda su propiedad. Esta hereicia les demandata la obligacion de cuidar a sus padres en su ancianidad. Tanto los derechos como las obligaciones eran escrupulosamente registrados ante testigos y firmados por ambas partes.

Esto nos aclara el por que Abraham pensaba que no le quedaba otro camino.

Ante este hacho Sara propone ura solucion, también con siderada posible ya que era costumbre en su país de origeñ y se hallaba convenientemente reglamentada; la encontra mos en Gn. 16:1-4 donde se lee: "Mira, Yhuh me ha hacho estéril; entra, pues, a mi esclava, a ver si por ella puedo tener hijos..."

Trece años mús tarde, Abraham ve el cumplimiento de la promesa, Sara concibe un hijo suyo que colma de gozo a los ancianos púdres. La historia, como resulta obvio, tiene un final feliz.

Comparando ambos personajes vemos que para Etaria, la solucion es un hijo que le aseoure uria descendencia sobre la cual no se le promete nada.

Para fibraham, la solución es también un hijo, pero incluye la promesa de una numerosa descendencia.

A Etana se le indica buscar.

A Abraham se le da una promesa, debe esperar. 
Ambos personajes crar al iniciar sumision. De Etana, no sabemos reaimente si logró el objetivo, pareciera ser que no fue así.

Abraham, oro y obtuvo respuesta logrando su objetivo en cuanto a desceridencia abundantemente (14).

\section{c) Joss de Juda y Etana}

Ambos son Reyes y los dos terminan en la hora de su muerte en forma similar en cuanto a sepultura.

En el relato de Etana, Ios senultureros llevan sus miembros a las llanuras, a campo abiertio... Notese que la orden que se da implicaria un cierto castigo: "Que pastor y zagal, leon y bestia salvaje, vean su fantasma (etinmu)" Con 10 que aquí hay una idea tipica en lo que a muerie des honrosa se refiere, la que se cumple aparentemente. Esté tipo de actitud corresponde a lina sitación de reprobación, desprecio y castigo, para que el espiritu del difunto no tenga el descanso que debería tener, al ser sefultado donde corresponde.

En Joas de Judá vemos gue luego de un reinado auspi cioso at stis cumienzos, va decayendo con el correr del tiempo y llega a una situación de tal deterioro que, final mente, sus siervos mis cercancs lo asesinan. Luego se or= dena la sepultura de el fuera de los sepulcros reales: "en la ciudad de David, pero no en los sepuicros de los reyes" (2 cron. 24:27).

Posiblemente Etana fue tratado de ese modo a causa de su fracaso. En el caso de joas, nos encontramos frente a un rey fracasado, culpabie de homicidio y a quien el pue blo sindica como responsable de las derrotas hacionales. No es estraña, pues, su sepultacion con deshonor.

\section{d) La instancia politica}

otro angulo de comparación es la instancia politice. Fn Etana subyace un trasfoncio de evidente intencion poli- 
tica, que sin ser menciunado espccificamente, se trasluce en algunos de los capitulos de este trabajo.

"La transmision de la autoridad de un gobernante efec tivo a otro, de su propia familia, que tenía la natural ventaja de asociación con su padre, pero no habia sido lla mado a! servicio, confrontaba a sumerios y semitas en ia antigua Mesopotamia y en todas partes en el Antiguo oriente con un problema, la realidad de la cual se quiere sa lir, indicado por el deliberado intento de autentificar la sucesion" (\$5).

Cabe hacer presente que en esta instanaia hoy que dis tinguir el concepto que se tiene del rey: un sar "Linitado ante los dioses"que es caracteristica en la realeza mesopotamica, a diferencia de Egipto, donde el Furaón era mira do como la encarnación del dios-sol Ra (15).

Selo excepcionabente un rey mesopotámico clama el status de dios, Närain-Sin ( $9 \%$ )

Asf que "en vista del problema de sucesión real como una regla prectica en coniraste con ei ideal denocrátice, es significativo que los antiguss reyes mesopotúmicos acen tuaran su status como "entrinzados" por un dios.

Los reyes mesopotamicos buscaban preservar su nombre y asi también lo trásunta Etana cuando ruega a Shamash: "Quita mi carga y produce para mi lin numbre" (Heoasirio III).

Si enfocamos ahora nuestra atencion a la vision hebrea de monerquia, encontramos que en prifier lugar, el verdadero rey es D's. Y que el rey que ha sido puesto sobre el pueblo, curiple su mandato por voluntad divina y para servir al pueblo. Su reinado debe ser un ejemplo para el puebio en 10 que a obediericia a la voluntad de $D$ 's se refiere, y esta vo Juntad de o's no es declarada por el rey mombre sino por uñ profeta.

Los relatos acerca de la institución de la monarquía se nos presentan bajo maticss iuy diterentes, dependen al parecer, del grado de simnatia que el narrador sintiera por la dinastía dávidica.

For lo general, los criticos se limitan a distinguir 
dos grandes conjuntos en los relatos concernientes a la ins titucion de la monarquia (1 Said. 7-15): uno favorable y otro hostil al principio monarquico.

Sin entrar ahora a profundizar en estos detalles, dire mos que una vez establecioo el reico y posteriormente la dí nastía (Davidica), nunca un rey pretendio asuinir categoriadivina. Sí debía considerarse siervo de D's, quien era el verdadero Rey, debia cumplir con la voluntad de El y actuar como pastor del pueblo.

Ass pues, en ambas concepciones la realeza surge dor voluntad divina, pero su posteicior desarrollo marca una gran distancia en cuatio al ideal puesto en práctica.

3. GENEROS LITERRRIOS - CORPARACIONES

a) Definiciories

A continuación daremos una brevisina definicion de los términos fábula y epopeya.

\section{Fśbulà:}

La fábula es definida como rumor, cuento, hablilla. Re lato mendaz. Ficcisin con que so encubre una verdad. Composicion literaria en que por medio de una ficción alegerica se da una enseñanza moral. Suceso o acción ficticia en la que se narra o se iepresenta para deleitar. También se usa la definicion para referirse a cualquiera de las ficciones de la Mitología.

\section{Epopeya:}

En la Epopeya se incluyen los poemas narretivas extensos de elevado estilo, que ciescriben una acción grande y pa blica, con personajes heroicos o de suma importancia, y eit el cual interviene 10 sobrenatural o maraviljoso.

También se incluyen agui, los hechos gloriosos, dignos de ser cantados Épicamente. 


\section{b) Fábula y sentido juridico}

Nos encontramos ante la faiulnea historia de las -en principio- muy anistosas relaciones entre una serpiente y un sgilila. Con posterioridad, el relato nos informa acerca de la traición del aquila, por cuya razón la acongojada serpiente llora y clama justicia ante el dios Shamash.

Shamash haciendose eco del reclamo, instruye a la ser piente para castigar ricbidamente al aguila mediante una trampa. Y, as acontace: el águila cae en la trampa, alli es desplumada, se le arrancan sus alones y le cortan sus garras, y finaimente, es arrojaca en ua pozo.

La fábula nos presenta una visión tipica dei sentido de justicia mesopotámico. Basta recordar -sin entrar en mayores detalles-, que en el escigo de Hamurabi, por ej. el rey pretenda haber sido comisionado por los dioses para actuar como gobernante, sabio y justo y para juzgar a su reino.

En nuestro relato (fabula) se indica que "Ninguna tia ra habia sido ceñida, ni corona...", elío supone que no existía rey ni habla reino y, por ello, habia qle clamar por justicia directamente ante los diosas: en este caso el roclamo es presentado ante sfanash.

Apreciamos que el frimcipio besico de la justicia mesopotámica esta centrado en "el pago ineludible de la (o las) falta(s) cometioa(s)". Asi, un ladrón debe hacer la restitucion $y$ un asesino debe pagar con su vida la otra vi da. Encontramos tambien matices que indicaban la forma de aplicar justica para caca clase social.

En la fábula se cometió un crimen contra la cría de la serpiente; para un caso puntual como este el código tiam murabi 14 señala:

"Si un ciudadano ha robado el hijo de un ciudadano, sers muerto".

Debenos recordar que existen codigos mas antiguos que el de hammurabi: el Coúgo cie Lipitishtar de Nippur, escri to en sumerio, uno o dos siglos mas ciritiguo que el de Hammurabi, muy similar a este $y$ contiene leyes identicas en varios casos. Precursor de los anteriones es el codigo del rey Eilalama de Eshuma, que reinú unos 300 años antes de Hammurabi. 
Más antiguos que los señalajos es el codigo Legislativo de urrarrmu y $\in l$ que 1 laria la atención por contener leyes mas humianas que cualesquiera de las conocidas en los códigos que le precedieron.

Coincidimos con S. Moscati cuando señala que la vida de la antigua sociedad babilonica y asiria nos parece basada en un orgánico sistema de leyes cuyas raices hay que buscar en la época sumeria y que pervive, desarroilandose, en la semitica. El derecho constive para los filieblos de piesopota mia, una tipica y fundamental categoria del persamiento, inclinato por instinto a converti ${ }^{\prime}$ las costumbres en normas, 10 que no daja de ser un aspecto de apiel cilto del orden con el cual se hacía coinciúir la existericiá.

Hacemos notar que en la Biblia no es posibie ellicontrar un tipo de relato fabuloso en el que se den los elementos que señalamos en Etana. Pero,prescindiendo de este hecho puritual, ericontramos en Israel lejes que iiluestrai gran semejanza con las leyes de Hammurabi. Hay sí, ciertas diferen cias fundamentales, debidas principalmente a diferentes con ceptos en cuanto a los derechos de los seres humanos y a la santidad de la vida.

Tambien debemos recordar que muchas de las leyes de Ham murabi no muestran ei absolubo ninguna semejanza con las leyes biblicas. Para quien las haya estudiacio resulta covia la relación innegable eritre aibos códigos.

\section{c) Eporeya-descendencia Divina}

La gran mayorsa de los estudiosos coinciden en que en su épica, el mito de Etana piantea el probiema de la suce sión. John Gray, por ejemplo dice: "El objeto deluviaje de Etana, sin embargo, es significativo. Es para alcanzar la planta del nacimiento, que su "afliccion" (carga) o impotencia (incapacidad) pueda ser derogada (oestruida, expulsada) y "un noinbre" sea producido para él".

Esto inoica que el problema es el de "I a sucesión dinás tica"; problena comán en dos leyendas reales entre textos ca naaritas de Ras Shumra. 
De la recurrencia del motivo del vuelo de Etana en la gi iptica, diferentes autcres deducen que la mision con cluyó felizmente ya que sólo una hazaña exitosa sería récoroda. Si esta conjetura es correcta, el hallazgo de la planta del nacimiento puede haber sido usada para mantener los derechos diricsticos.

La epopeya de Gilgamesh, junto a consideraciones sobre los IImites de la autoridad real y habiendo muestras evidentes de una Constitución, muestra a la realeza como una emergencia oportuna instituida "ad hoc" y no visualizada como necesariamente permanente.

Pero en í competencia entre ciudacies-estado rivales, los conflictos tendian a ser prolongados o recurrentes, de ahs que la autoridad ól rey deviene en pormanente aún cuardo el monarca mismo la consideraba como una mision (comisión) del Divino Rey.

No obstante elio, el rey gozaba de un peculiar culto, que en la concepción del Cercano oriente, permitia to mar parte de él a todos los que estaban alredejor del rey y especialmente a los miembros de su propia familia, que eran los mas idoneos para slicederle; de lo que se deduce que, teóricamente, ia realeza era un recurso iemporal.

Hay algo mas que resalta de esta epopeya y es la insistencia en buscar la descenciencia en una mujer determinada "la preferida".

"Pero aunque la suegra de el hacía atractiva a la reina para el y el chambelan del bitanu... las mujeres del ha rem su deseo sĉio se exaitaba por la hermosa Mudam". (CFr. Asirio I, fragmentos diversos)

Este hecho es frecuente en otros relatos y asi tenemos a: Etana que despliega todo un extraordinario esfuerzo sólo por perpetuar su descendencia en un heredero real que sea hijo de la "hermosa Mudam". Las historias de Abraham y Sara, Ana y Elcana, Jacob y Rebeca, quienes, aun que no pretenden perpetuar una monarquia ni constituyeri todos casos de falta de descendencia. la busqueda de esta se centra en torno a una mujer "preferida". Si avanzamos un poco más en el relato bíblico encontramos el caso David-Betsabé-Salomón. Alli la continuación de la dinastía ie es otorgada al hijo de la mujer preferida Puede con cluirse que aunque se trate de situaciones diversas, el 
motivo no es extraño a la literatura de la época.

As s como se evidencian semajanzas, encontramos tambien diforencias. Por ejemplo:

1) Etana, en busca de solución a su problama, acude a "pedir" antie la divinidad, Shamash.

Abraham espera el cumplimiento de una promesa y ruega a JHV para que recuerde lo prometido.

2) Etana desea engendrar un hijo de midam, para perpetuar su nombre y estabiecer una dinastía apoyada en la designación divina.

Abraham desea el hijo de la promesa para fundar un pueblo y al igual que Etana, perpotuar su nombre.

3) Etana viaja pare buscar solución a su problema. Sube mon tañas, vusla montando un zquila, pero debe volver al punco de origen oara estabiecer mejiante la descendencia una monarquia hereditaria.

Abraham tambiên viaja en pos de la promesa. La diferen cia radica en que el no volverá al punco de origen, debe ir a una tierra nueva, la iierra Prometida. fidemás, no recurre a vegetal alguric para que Sara conciba.

4) La oracion esta presente en ambos:

a) Etana ora: "Oh señor, que salga de tu boca: otorgame la planta del iacimiento, quita mi carga y produce pa ra mi un nombre" (Cfr. Neo-asirio III).

b) Alraham también ora: "Señor juV, ¿qué me darás, sien do as 1 que ando sin rijo.... mira que no me has dado prole" (Gën. $15: 2,3)$.

5) Ambos reciben una respuesta precisa:

a) A Etana se le responde "sigue tu camino, cruza la montaña; al ver un pozo, examina su incerior, dentro de el yace un aguilá El te mostrarg la plarita del na ciniento" (Neo-asiono III)。

b) La respuesta para Abraham es: "Luego vino a $\in l$ la palabra de JHV diciendo: no te herederá este, sino un hijo tuyo sera el que te heredara. Y lo lleve fuera, 
y le dijo: mira ahora los cielos, y cuenta las estre lles si las puedes conter. Y le dijo: asi será tu descendencia". (Gen. 15:4,5)

Abraham-Etana: son dos personajes inportantes porque han sico ilamadosa iniciar algo, un pueblo escogido, un reino para el pueblo.

"fero JHV habia dicho a Abranam: vete de tu tierra y de tu parentela, y de la casa de tu padre, a la iierra que te nostrare. Y haré de tí una nación sraride, $y$ te bendecire, y engrandecere tu nombre, y seres bencicion" (Gen. 12: 1,2)

"Ishtar, un pastor para el pieblo...... $\gamma$ un rey busca para la ciudad" (Neo-asirio I y III).

Ambos buscan descendencia, Abraham de su mujer legiti ma, Etana de la mujer preferida.

En el relato de Ana y Elcara encontramos a otra esposa preferida de su marido $y$ sis descendencia, porque era esteril. También Elcans tenca citra esposa, Penina, y Esta si tenía hijos (Cfr. 1 Sam. i: $1-20$ ).

La demostración por parte de Eicana en cuarto a prefe rencia está rogistrada en el nomento de repartir las par= tes para sacrificio, como se lee "pero a Ara daba una farte escogida; porque amaba a Ana, aunque iHb no le habia concedido tener tijos".

Penina hacia escarnio de su rival "enojandola yentris teciéndola, porque JHV no la habîa favorecido.

As q que en una ocasión especial, fna se levantó y se dirigio al Templo donde "con amargura de alma oro a JHV, y llcrs abuncaitemente", al mismo tiempo hizo voto, prone tierido que si le era concedida la berdicion de la materni dad y le naciera hijo varsn: "yo lo dedicaré a jHV...".

Se repire el caso del relato de Etara: la mujer predilecta no es capaz de concebir: pero a diferencia del an terior, aqui la mijer ruega a $D^{\text {is }}$ para obtener io deseadó 
y D's escucha su petición. No hay que buscar plantas, ni ascender montañas, estamos ante la presencia del que tiene poder en su Palabra.

En el relato de Jacob, Raquel y Lea encontramos más detalles similares al de Etana. De las dos esposas de Ja cob, la preferida es estéril.

En Gên. 30:14 leemos:

"Fue Rubén en tiempo de la siega die los trigos, y hallo mandragoras, y las trajo a Lea su madre; y dijo Raquel a Lea: te ruego que me des de las maridragoras de tu hijo".

Pareciera que nos encontramos ante otra semejanza: una plóta a la que se atribuye poderes especiales: La mancirgora afficinarum, la que según la creencia popular poseía cualidades afrodisiacas al mismo tiempo que asegu raba la concepcisil.

Si bien es cierto Raquel disfrutaba de la mayor par te del afecto de su esposo, no podia estar contenta mieñ tras su hermana lea la sobrepujara en lo ques para todó oriental es ei mas importante de los deberes de una esposa: la maternidad.

La Biblia nos menciona el caso de Rebeca, esposa de Isaac, quien habia esperado unos 20 años, pero esperar af́rontando la competcricia hizo que Raguel se impacientara y que con celos mal reprimidos censurase amargamente a Jacob.

Como en el caso de Sara-Abraham, buscaron una solución intermedia a través de la sierva de Raquel, Bilha (Gén. 30:3).

Finalmente, "se acordo D's de Raquel" y el problema se resolvis por voluntad o providencia divina. He aqui que entences ella dijo:

"D's ha quitado mi afrenta" (Cfr. Gen. 30: 22, 23).

Cábe señalar que en el Antiguo Oriente, una mijer estéril, no era compadecica sino despreciada, y se consi deraba la falta de hijos cono una verguenza y una maidición(18). 


\section{Cosmovisiones subyacentes}

A traves de la lectura de ios dexios biblicos y el texto mesopotamico, se revelan dos diferentes modos de ver la realidad, dos concepciones del mundo: la del hombre mesopotámico y la del nombre nebreo.

En Mesopotamia, por un lado, teremos una religion basada fundamentalmente en las creencias sumerias las que, además de proporcionar una guia espiritual y ética para los problemas humanos, ofrecla una explicacion de los misterios fundamentales de la vica y de la muerte.

Akkadios, babilonics y asirios fueron los herederos de los dioses, las practicas religiosas y la colorida mi tologia sumeria.

Los habitantes del valle mesopotámico eran esencial mente politeista. No obstante el rümero y la compleji = dad del panteón creajo por los sabios, Este funcioncia en armonia: un ejemplo de e!lo nos 10 da el mismo texto de Etana,cuendo nos presenta a "los Grandes Aantinnaki" sentados, deliberando sobre los ciestinos de la timanidad

Los dioses estaban closificados jerarquicamonte de acuerdo a su importancia, influencia y poder. Los de mas alta categorga, como lo eran Annu, Enili, Enki y Ninhursag, eran los que creaban y planificadan los componentes del universo y los ponian a cargo de uno u otro de sus descendientes, los dioses administrativos.

Para el mesopotámico, la creación del mundo no habia sijo ni dificil ni trabajosa, puesto que una vez que los dioses decidieron lo que querían hacer, no tenian na da más que expresar su plan de accion para realizarlo: la palabra de la divinidad tenía el poder, por si misma, de crear algo de la nada.

El hombre -modelado de barro y la sangre de un dios sacrificado-, habia sicio creado con una sola finalioad: servir a los dioses, proporcionândoliss comida y abrigo, de suerte que pudieron tener un sosiego de las labores cie la vida diaria. 
Por ello, el hombre fatalista y resignado crela que era impotelite ante la colera divina y aceptaba de manera sumisa las decisiones divinas.

La concepción de la creación estaba pensada en térmi nos netamente humanos, de tal suerte, que el mesopotámicó penso que el universo estaba regido por seres superiores que el imagino con caracteres antropomorficos: seres que poseian familias, tenian necesiodes, clialidades y defectos.

Aparentemente Etana tiene esta idea en mente cuando eleva sus plegarias a Shamash y tombiar cuancio de acuerdo con el águila emprende la aventura del vuelo épico que conocemos.

En el mundo biblico en cambio, el poijteísmo de los pideblos de la Época oponía su monotelsmo hebreo que pro clamaba que un 0 's rige sobre todo lo que hay en El mundo.

Ese D's es un ser terrible en su justicia $y^{\prime}$ trenendo en su santidad. Es el creador, sosten y rector del mundo, creador de la especie humana, amo de su destino, juez de sus actos y guía de su historia.

La Biblia hace hircapié no en la existencia de un D's, sino de un Dis único.

Cuando se dice "Sh"ma Israel, A" Elcheinu, $A$ " ejad" se establece su unicidad de manera irrefutable.

Del mismo modo cono difiere en clianto a lo divino, el texto biblico difiere del mesopotémico en cuanto a lo humano.

Ciertamente el nombre es paite de la naturaieza, pero no se halla totalmente confundida con aquélla por cuan to él (el hombre) es la culminación del proceso de forma= ción del cosmos.

El hombre aunque ubicado muy por debajo de D's, esta por encima de las bestias y objetos fisicos que la divini dad ha creado, dotandolo de libertad, y con una finalidad diferente a la que se evidencia en la concepcion mesopotúmica, por cuanto ha sido creado para que señorease la tierra y los seres vivientes. 


\section{CONCLUSION}

La Biblia es un texto artiguo, un registro historico y como tal debe estudiarsela a la luz del conocimiento de la época en la cal fue escrita.

En esta afimación no hay nada de hereje porque la fe depende de sucesos historicos, cosas que de hecho suce dieron. Los sucesos relatados y explicados en la Bibilase pueden situar juntio a los sucesos conocidos for otras fuentes historicas. La Biblia misma consta de documentos tan antiguos y tan historicamente verificables cono cua lesquiera otros.

Poseemos muy pocos escritos antiguos que describan los mismos sucesos que describe la Biblia $y$, en cualquier caso, dos observaciones rara vez describieron un suceso desde el mismo punto de vista.

Munque pocas veces se encuentran relatos paralelos de los mismos sucesos, con frecuencia se encuentra ejemplos de costumbres y acontecimientos muy parecidos a los descritos en la Biblio, aunque no están de mocio alquno relacionados. En esto nay que ser cauteloso ya que una semejanza superficial puede ser engañosa.

Ass pues, en ei caso presente, hemos quarido efectuar un analisis companativo entre la biblia y ua antiguo texto mesopoctáni ico.

La idea primera era la de tomor un libro biblico y un personaje y contrastario con el relató de Eiana.

Al adentrarnos en nuestro estudio, notamos la imposibilidad de poder realizar lo propuesto originalmente.

Revisando el documento nesopotamico vimos que el orden de las tablilias que nos han llegado no corresponien al orden logico de los reiatos. Frocedimos a realizar una ordenación de las mismas.

Del texto mesopotámico podemos decir que narra dos re latos: uno fabuloso y otro epico. Aparentemente ambos existieron por separado durante tienpo indefinido. Con el correr de los años, décadas o sigios, ambos se refundieron en uno sola historia, que es la que nosotros conocemos por 
tablillas existentes. Fata unión se hizo a partir de un elemento preciso que aparece en ambos: "el sguila".

Al realizar una comparacion con el Antiquo Testamento logramos detectar aparentes coincidencias entre ambos. Las coinciciencias, ya sea lexicales, de motivos o situaciones parecidas, corresponden, en la abrumadora mayoría de los casos, a situaciones insertas en contextos diferentes.

Como "grän motivo" distinguimos en Etana el interes en establecer una dirastia que se suponc cuenta con el apo yo divino y que, siendo asi procede a justificar su exis = tencia dandole un origen mítico-fabuloso.

En el Antiguo Testimento, en cambio, al encontrar coincidencias, ya sea lexicaies o a nivel de situaciones y/o motivos, el problema y su solucion apuntan a propesi tos muy distintos.

$Y$ aunque en algunos detalles hay -aparentemente-mu cho en común, la fe en el telón de fondo es algo totalmeñ te diferente.

A ello se suma el hecho de que en el pueblo hebreo la historia se desarrolla con individues oue se identifican con una mision histórica como pueblo, dejando finalmente de lado lo personal ista que, si bien es importante, no lo es en lo final del objecivo nacional de Isrál. 
NOTAS

(1) MOSCAT, S. Las antiguas civilizaciones semiticas, D. 36 .

( 2 ) Id. p: 38 .

(3) WOOLLEY, L. Mesopotamia y el Asia Ariterior. cap.iIl, p. $82-83$.

(4) PARROT, A. Sumer, p. 188,18 m. 226.

(5) La ottención de "un nombre", o dicho de otro modo, el engenárar un hijo sefrala la ausencia total de esterilidad y en las socieciades orientales se la consideraba como una bendición divira.

(6) La palabra es de vital importancia en las culturas del finticuo oriente y, en un comienzo, se le asignaba una significacion mágica. Sa crea merced al poder de la palabra. Sobre el particular, ver de Poriariy, L. "Word as Power in the fincient Near East" en: Orienta iia, 1975 .

(7) La planta del nacimiento esta indisolublemente ligada al problema de la cescendencia para la "obtención del nomure".

(8) Se refiere a una acción de gracias por la Justicia de D's.

(9) En relación al rey David, imploranco perdón.

(10) Es una declaración de confianza absoluta en Dis.

(11) El versiculo dice: "Tá que decias en tu corazon: subj ré al cielo, en lo alto, junto a las estrellas de D's levantare mi trono y en el monte del testimonio me sentaré..." El versiculo está referido a la caída del reino de Babilonia.

En el texto mesopotámico, se refiere al águila, que piensa que puede transgieder el juramento pactado con la serpiente $y$ escapar al castigo. 
(12) El versirulo biblico complete dice: "padre mio, padre mio, carro ce Israel y su gente de a caballo". Es el momenico en que Elías asciende a lo alto.

El texto mesopotámico hace alusion a ios consejos que el aguilucho da al aguila, su padre.

(13) For ello encontramos similitudes tambien entre cierto tipo de textos biblicos y la literatura egipcia, por ejemplo, La Sabiduría de ptahocep.

(14) liumerosas tribus han hecho remontar su genealogia has ta Abraham. Los ârabes madianitas, ismaelitas y otras tribus descendientes ce Cetura, los edonitas y los israelitas; todos fueron descendientes de Abraham. (ver Comentario Biblico Adventista, tomo I, p. 309 ).

(15) GRAY, J. Hear Eastern Mythology, p. 52.

(i6) Idem, p. 53 .

(17) Id. ibid.

(13) Ver Comentario Biblico Adventista, Tomo I, p. 405. 
BIBLIOGRAFIA.

\section{DOCUMENTOS}

- ETANiA, Jaime foreno, trad. Edic. Depto de Historia, Fa cultad de Ciencias Humanas, Universidad de Chile, 1979.

- LISTA DE PEYES SURERIOS, Jaime Moreno, trad. Ed. Departa merito de Fistoria, Facultad de Ciencias Humarias; Univer = sidad de chile, 1977.

BIELIOGRAFIA GENERAL

CAMBRIDGE ANCIENT HISTORY, The Vol. 2: "Early history of the Middle East". CAmbridge University Press. London, 1971. COHENTARIO BIELICO ADVENTISTA

FRANKFORT, H. Reyes y dioses, Alianza Universal S.A. Madrid, 1981 .

GRAY, J. Near Eastern Mythoiogy, London, 1975.

HAWKES, J. The first Great Civilizations, Penguin Books, U.S.A. $197 \%$

IRHIN, K. A。 / FRARKFORT, H. Y Ho El pensamjento prefilo sofico II; Los hebreos. Ed. F.C.E. Mexico, 1908 (toreviários 98).

Israel Pocket Libr. History from its beginning to 1880 . Ed. Keter Books, Israel, Jerusaiem, 1970.

JACCBSEN, TH. The intellectual adventires of man.

KRAMER, S. N. La cuna de la civilización. Colección Grandes Épocas de la humanidad. Time-Life, Nënerlands, 1974. 
KRAMER, S. N. La historia comienza en Sumer. Ed. Aymá S.A. Barcelona, 1905 .

LLOYD, S. El Arte del Medio Oriente Antiguo, Librería Editorial Argos S.A. Barcelona, 1952.

LODS, J. Israel desde sus origeres hasta el siglo VIII.

Ed. UTEHA, Miadrid.

MOSCATI, S. Las antiguas civilizaciones semiticas, Edit. Garriga S.A. Barcelona, TSt4.

NELSON, W.M. (Editor) Diccionario llustrado de la Biblia. Edit. Caribe, liami, 1977.

NICHOL, F.D. (Ed.) Seventh Day Adventist Bible Commentary. Ed. Review and Herald Publishing AsSociation. Hâshington D.C. 1957 .

PARROT, A. Súmer. Colección Universo de las Formas, Edit. Aguilar S.A. Madrid, 1969.

PIRENAE, J. Civilizaciones Antiguas, Edit. Louis de Caralt, Barcelona, 108T.

FRITCHARD, j.B. La sabiduria del Antiguo oriente, Edic. Garriga S.A. Eercelona, 1960.

PRITCHARD, J.B. Ancient Near Eastern Texts.

RATTEY, B.K. Los hebreos, Ed.F.C.E. (Breviarios 111), MEX XICO $\{966$.

SCHMOCKEL, H. El país de los sumeros. Ed. Eudeba S.A. Bue nos Aires, 1965.

TPAT, A.D. (Comp.) Manual Blblico Ilustrado, Edit. Caribe, Miami, 1976.

HILSON, H. y JACOBSEN, T. El nonsamiento prefilosorico I. Egipto y Mesopotaria, Ed. F.C.E. (Brevierios g7), Mexico T५58.

WIESNER, J. Antiguo Oriente (Colección Historia del Arte Universal, Ne 2) Eúic. Poretón, S.A. Bilbao, 1367. 
WOOLLEY, L. Mesopotamia y el Asia Anterior. Col. El Arte de los fueblus. Ed. Selx Barrát Praxis S. A. Rarcelona, 1953 .

WOOLLEY, L. Digging up the past. Fenguiit Books. London.

ZEURos, C. L'Art de la Mesopotamie. Ed. Cahiers d'Art. Paris, 1935. 


\section{INDICE}

Presentación .................... i

I. Problemî́s históricos............. 1 - 4

II. Texto de Etana............. 5

1. Generalidades sobre el texto ..... $5-7$

2. El Texto: ........... . . 8

a) Relatos cronuljgicos........ 9 9 - 27

b) Relato "logico" $28-39$

III. Critica historica .........440-44

IV. Etana y el Antiguo Testamento:

Estudio comparativo......... 45

1. Comparación a nivel lexical...... 45

a) Aclaracicnes subre el vocabulario usudo en ambos textios ...... $45-53$

b) Coincidencias lexicales ..... $54-56$

2. Comparacion a nivel de situaciones $y$ motivos

a) Un "frutc prohibido"....... 57

D) Elescueda de descendercia . .... $58-60$

c) Joás de Judá y Etana ....... 60

d) La instancia polifica ..... 60-62

3. Generos literarios. Cumparación . . . 62

a) Fúbula y epopeya ......... . . 62

b) Fábula y sentido jurifico . . . . $63-64$

c) Epopeya: descendencia divina.... $64-58$

4. Cosmovisiones subyacentes ...... $69-70$

v. Conclusion ............ $71-72$

VI. Motas ........... $73-74$ 
VII. Bibliografía . . . . . . . . . . $75-77$ VIII.Indice . . . . . . . . . . . . $78-79$ 